\title{
On the Political Complementarity between Health Care and Social Security ${ }^{x}$
}

\author{
Carlos B ethencourt \\ Universidad Carlos III de Madrid and Universidad La Laguna \\ Vincenzo Galasso \\ IGIER, Universidad Carlos III de Madrid and CEPR
}

November 2000

\begin{abstract}
A bstract
The dramatic rise in the US social security and public health expenditure is only partially explained by the demographic trend, and may be due to the political complementarity between these two programs. We suggest that public health care increases the political constituency in favor of social security, and viceversa. Speci..cally, public health decreases the longevity dixerential between low and high-income individuals, therefore rising the retirement period, and the total pension bene..ts of the former relatively to the latter. This increases the political support for social security among the low-income young. We show that in a political equilibrium of a two-dimensional majoritarian election, a voting majority of low-income young and all retirees supports a large welfare state. Its composition between public health and social security is determined by intermediate (median) income types, who favor a combination of the two programs, since public health increases their longevity enough to make social security more attractive.
\end{abstract}

K eywords: Endogenous Longevity, Subgame Perfect Structure Induced Equilibrium. J EL Classi..cation: H53, H55, D72.

${ }^{\natural}$ Corresponding author: V incenzo Galasso, Istituto di E conomia Politica, Università B occoni, via G obbi 5, 20136, Milano, galasso@eco.uc3m.es. Carlos Bethencourt: cbethenc@ull.es. 


\section{Introduction}

In the last few decades, the US have witnessed a dramatic increase in social security and public health care (M edicare) expenditure. Since both programs are mainly targeted to the elderly, the aging process represents a natural candidate to explain their rapid expansion. However, as argued by Mulligan and Sala-i-M artin (1999), demographics alone may not be suc cient to account for the full extent of this rise. To qualify this statement, ..gure 1 displays the increase in the level of social security and public health care (Medicare) expenditure per elderly person, i.e., the ratio between social security and public health care (M edicare) expenditure as share of GNP and the number of elderly in the population, from 1960 to 1999. In a nutshell, the share of the elderly in the population has risen, and each of them has been receiving more resources, particularly as public health care. Moreover, this trend is expected to continue, thereby posing serious concerns on the sustainability of both systems.

The goal of this paper is to explain the contemporaneous expansion of social security and public health care. We suggest that the key element lies in the political complementarity between these two programs, which induces a multiplicative response to the aging process. With political complementarity, we characterize the fact that the existence of a social security program increases the political constituency in favor of public health care, and viceversa. The seed of this intuition was in Philipson and Becker (1998), who argued that social security induces the elderly to increase their private investment in health care, because the existence of an annuity - the old age pension - rises the value of longevity.

We identify a new link that goes from (public) health care to social security. Expenditure in public health increases longevity in a non-linear way, as its exect tends to be larger among low-income individuals than among well-ox people (see $A$ nand and $R$ avallion (1993), and Cutler and Richardson (1997 and 1998)). However, richer individuals tend to live longer, since income has a protective exect on health (see Deaton and Paxton (1998 and 1999) and Smith (1999) among others). Thus, for a given distribution of income, the expenditure in public health contributes to decrease the longevity dixerential between rich and poor individuals. As a result, the retirement period, and thus the total pension bene..ts, increases more for low-income individuals than for high income individuals, therefore rising the returns on social security for the low income workers, as opposed to high income ones.

The main contribution of the paper is to show that, for a sensible representation of the two programs, the political complementarity between social security and public health care exists, and pushes the size of the welfare system beyond what the demographic structure alone would have implied. Social security and public health care are sustained as a politicoeconomic equilibrium outcome of a dynamic majoritarian voting game. A voting majority of low-income young and all retirees supports a large welfare state, as in Tabellini (1990) and in Conde-Ruiz and Galasso (1999). Its composition between public health and social security is determined by intermediate (median) income types, who favor a combination of the two programs, since public health increases their longevity enough to make social security more attractive. On the other hand, in the case of exogenous longevity, that is, when public health has no exect on the longevity dixerential, there could be no political complementarity running from public health to social security. Every individual would either choose pure public health or pure social security, and the dimension of the welfare 
state would be lower.

Three elements are crucial to our explanations. First, we emphasize the protective exect of income on health. As shown by Deaton and Paxton (1998 and 1999) and Smith (1999) among others, high-income individuals live longer. Second, we consider the redistributive exects of the health care expenditure in its double role of increasing the quality of life and of rising longevity. Although the largest share of the health care expenditure is targeted to the elderly (see Auerbach, Gokhale, and Kotlikow (1992) and Cutler and M eara (1997)), there are evidence of within-cohort redistribution in favor of the lowincome individuals (see van Doorslaer et al. (1999) and Lee, McClennan and Skinner (1999)). A nalogously, the increase in longevity induced by the public health expenditure is stronger among low-income individuals than among high income ones (see A nand and Ravallion (1993), and Cutler and Richardson (1997 and 1998)). These aspects are critical to explain why health care is appealing to low-income individuals.

Third, we underline the intragenerational redistribution component of social security, due to the combination of social security contributions that are proportional to the labor income (up to a maximum) and regressive bene..ts. For the US, Boskin et al. (1987) and Galasso (2000) show that, within a given cohort, low income families obtain larger internal rates of return from social security than middle or high-income families. Like in Tabellini (1990) and Conde-Ruiz and Galasso (1999), because of this within cohorts redistribution element, social security may be appealing to low-income young.

We introduce a dynamically ec cient overlapping generation economy with storage technology. Individuals dixer in their income, and therefore in their longevity. Agents value their old age consumption and total health care, which is provided publicly and privately. $P$ rivate health care is more eфcient in increasing the quality of life, and therefore in providing direct utility. Public health care is less ec cient in rising the quality of life, but it increases longevity. This exect on longevity is non linear, and is stronger for low-income agents.

The welfare state collects a proportional income tax on the young, which ..nances public health care expenditure to the old and social security transfers. Public health care is available in equal amount to every elderly person at the beginning of her old age, whereas the unfunded social security system pays out a lump sum pension during the entire retirement period, i.e., an annuity.

The size of the welfare state and its composition between the two systems are determined in a two-dimensional majority voting game by all agents alive at every election. As shown by Conde- Ruiz and Galasso (1999 and 2000), these types of voting games display two critical features. First, because of the multidimensionality of the issue space, the existence of a Condorcet winner of the majority voting game is not guaranteed. Second, if an equilibrium exists, in absence of a commitment device over future policies, young voters have no incentive to support any intergenerational transfer scheme. To overcome this problem, we follow Conde- Ruiz and Galasso (1999 and 2000) in adopting the notion of subgame perfect structure induced equilibrium, which combines the concept of structure induced equilibrium, introduced by Shepsle (1979), with the intergenerational implicit contract idea, originally presented by Hammond (1975).

The paper proceeds as follows: Section 2 describes the economic model and the welfare system. Section 3 discusses the voting game, and the equilibrium concept, while section 4 characterizes the politico-economic equilibria. Section 5 analyzes the case of exogenous 
longevity, and the results are compared to the endogenous longevity case in section 6 . Section 7 concludes. All proofs are in the appendix.

\section{The Economic M odel}

We introduce an overlapping generation model with storage technology. Every period, there are two generations of non-altruistic agents, young and old. Population grows at a constant rate ' $>0$. Individuals are endowed with a young age income, and retire in their old age.

A gents are assumed to be heterogeneous in their young age income, e, which is distributed on the support [e; e] $1 / 2<_{+}$, according to the cumulative distribution function $G(:)$. A $n$ individual born at time $t$ is characterized by an income level and will therefore be denoted by e 2 [e; e]. The distribution of abilities is assumed to have mean e, and to be skewed

$$
\mathrm{e}_{\mathrm{e}}^{\mathrm{e}} \operatorname{edG}(\mathrm{e})=\mathrm{e} ; \quad \mathrm{G}(\mathrm{e})>\frac{1}{2} \text { : }
$$

Income has a protective exect on longevity: agents with higher income tend to live longer than agents with lower incomes. This protective exect of income has often been attributed to the easier access that high income agents have to private health care. A Ithough recent studies have criticized this explanation, as well as the casual relation between income and health (see Smith 1999), the existence of a positive relationship between health and income, the "gradient," is uncontroversial.

For analytical simplicity, we choose to disregard the demand for private (and public) young age health care, and to assume that longevity is directly related to income ${ }^{1}$. Every agent lives until the second period. Longevity in the second period, i.e., the fraction of the second period during which an agent is alive, depends on her income, and on the level of public health care expenditure.

Public health care is assumed to have a positive non linear exect on the longevity of the agents. For a given level of public health expenditure, low-income individuals enjoy larger gains in longevity than medium-to-high income agents. In other words, longevity displays decreasing return to health care ${ }^{2}$. Additionally, we choose to abstract from the rise in average longevity, and to concentrate on the change in the longevity dixerential between low and high income agents. Unlike P hilipson and B ecker (1998), we are mainly interested in the within-cohort redistributive impact of the public health expenditure, because of its interesting spill over exects on the political decision on social security, rather than in the average longevity gains, which, for a given income tax rate, would just reduce the lump sum pension to all agents.

\footnotetext{
${ }^{1} \mathrm{~A}$ recent literature has analyzed the exect of income inequality on mortality. W ilkinson (1996) provided evidence that more income inequality increases the average mortality in a country, whereas Deaton (1999), and Deaton and Paxson (1999) found no evidence of a direct impact of inequality on mortality.

${ }^{2} \mathrm{~T}$ his greater exectiveness of public health care among the poor can be due to the higher initial longevity of the high-income individuals, and to the lower private health care consumption of the low-income agents. Evidence that, for a given level of income inequality, public health care has non-linear exects are in A nand and R avallion (1993) - for cross countries data, and in Cutler and Richardson (1997 and 1998) - for data on individual agents.
} 
The following longevity function, $\pm\left(e ; H_{t}\right)$, captures all these characteristics. It identi..es the fraction of the old age that a type-e individual born at time $t_{i} 1$ is alive for:

$$
\begin{gathered}
\pm_{e ; t}= \pm\left(e_{;} H_{t}\right)=e_{t} 1+E_{t} \frac{\tilde{A}_{i} H_{t}}{\bar{H}} \\
\text { with } E_{t}=\frac{e_{i} 1 i e_{i 1}}{e_{i} 1}
\end{gathered}
$$

where $\mathrm{H}_{\mathrm{t}}$ is the average expenditure in public health care at time $t, \overline{\mathrm{H}}$ represents the upper bound on the public health expenditure, $2(0 ; 1)$ is the longevity of the average type $e_{i}$, and $E_{t}$ is a measure of the distance of a type $e_{i 1}$ from the mean type $e_{i 1}$.

Notice that $e_{t}\left(1+E_{t}\right)$ represents the longevity of a type-e agent in absence of public health care. Then, the income is the only determinant of longevity, and its protective exect is assumed to be linear. In this case, the longevity dixerential between the poorest, $e_{e}=e$, and the richest, this longevity dixerential decreases, although the average longevity should rise. Since we disregard the latter exect ( $\underline{\underline{ }}$ is assumed to be constant), the public health expenditure rises the longevity of the individuals whose income is below the mean, but decreases the longevity of the others. This exect is shown in ..gure 2 for the mean income type, e, for a poor, e $<\mathrm{e}$, and a rich, e $>\mathrm{e}$, individual. In the limit, as the maximum amount of disposable resources is devoted to public health, $\mathrm{H}=\overline{\mathrm{H}}$, the longevity dixerential disappears, $t_{e}=\underline{\theta} 8 \mathrm{e}$

A gents value consumption and health care in old age only ${ }^{3}$, according to a CobbDouglas utility function:

$$
\mathrm{U}^{3} \mathrm{c}_{\mathrm{t}+1}^{\mathrm{t}} ; \mathrm{m}_{\mathrm{t}+1}^{\mathrm{t}}{ }^{\prime}={ }^{3} \mathrm{c}_{\mathrm{t}+1}^{\mathrm{t}}{ }^{\prime}{ }^{3} \mathrm{~m}_{\mathrm{t}+1}^{\mathrm{t}}{ }^{\prime}{ }^{\prime}{ }_{\mathrm{i}} "
$$

where $c$ is consumption, and $m$ is the health care. Subscripts indicate the calendar time and superscripts indicate the period when the agent was born.

As in Epple and Romano (1996), agents value public and private health care jointly, as a composite good, m. Public and private health care do, however, dixer. Public health care plays a double role: it provides medical services that improve the quality of life of the individuals, therefore increasing their utility 4 ; and it rises longevity, i.e., the quantity of life. On the other hand, in our setting, private health care may only improve the living standard of the individuals ${ }^{5}$. In particular, private health care is assumed to be more ec cient than public health in providing the medical services that rises the quality of life (see the empirical evidence in Currie, Gruber and Fisher (1995) and Cutler and Gruber

\footnotetext{
${ }^{3}$ T his assumption greatly simpli..es the analysis, but entails some costs. First, we do not model the demand for private (and public) young age health care, and simply assume that longevity depends on the income. Second, we abstract from saving decisions, that are known to be relevant for the political sustainability of social security, see Boldrin and R ustichini (2000), Cooley and Soares (1998) and Galasso (1999).

${ }^{4}$ Since Grossman (1972) seminal contribution, health care has been assumed to provide utility, either directly or by increasing the utility from consumption, as in Epple and Romano (1996) and Philipson and B ecker (1998).

${ }^{5}$ W e acknowledge that private heal th care does, indeed, increase longevity. T his exect is captured by the positive relation between income and longevity. Richer individuals are expected to spend more resources on private health and therefore to live longer.
} 
(1996)). Thus, at time $t$, the health care services provided to an old agent, $m_{t}$, is equal to:

$$
\mathrm{m}_{\mathrm{t}}=\mathrm{b}_{\mathrm{t}}+\mathbb{R}_{\mathrm{t}}
$$

where $b_{t}$ and $\mathrm{H}_{\mathrm{t}}$ are respectively the expenditure in private and public health care received by an old person, and $® 2(0 ; 1)$ measures the el ciency gap between private and public health care.

A storage technology allows to transfer one unit of consumption today into $(1+R)$ units of consumption tomorrow. Additionally, we assume that $\mathrm{R}>{ }^{\prime}$ ', and thus the economy is dynamically el cient. All private transfers of resources take place through this storage technology.

The budget constraint of a type-e agent born at time $t$ is

$$
c_{t+1}^{t}+b_{t+1}^{t} \cdot(1+R) e_{t}\left(1 ; \quad i_{t}\right)+t_{e ; t+1} P_{t+1}
$$

where $i t$ is the tax rate on income at time $t$. Young agents are endowed with an initial income, on which they pay a tax. They take no economic decision, and save their net income for future consumption. W hen old, they are entitled to a (one-time) public health care and receive a lump sum pension for the remaining duration of their life. They use their pension income and their saving to ..nance their private consumption and their expenditure in private health care.

There exists a fundamental dixerence between pension transfers and public health care. A pension transfer is a lump sum annuity, which is paid to every agent for the entire duration of her old age. Although the pension is lump sum, and thus unrelated to income, since high income people enjoy higher longevity, they will receive a pension for a longer period, thus collecting a larger pension income. In every agent's budget constraint, the pension is thus multiplied by her longevity.

A public health care program entitles the elderly to a medical service. How can we measure the extent to which individuals that dixer in their health status and longevity use this service? High income individuals have better health status, but they live longer, and may need more expensive medical services; whereas low income individuals have lower longevity, but may require a more intensive usage of the system while they are alive. For all individuals, however, the largest share of the cost of heath care is concentrated in the last six months of their life (see Lee et al. (1999)). Thus, we choose to consider public health care as a lump sum expenditure, which occurs only once during the old age.

At time $t+1$, an elderly person determines her demand for consumption and for private health care by maximizing her utility function, eq. 2.3, with respect to $c_{t+1}^{t}$ and $\mathrm{b}_{t+1}^{\mathrm{t}}$, subject to the budget constraint at eq. 2.5. We call $\mathrm{W}_{\mathrm{e} ; \mathrm{t}+1}^{\mathrm{t}}$ the net wealth of a type-e old agent at time $t+1$ :

$$
W_{e ; t+1}^{t}=e_{t}\left(1 ; \quad i_{t}\right)(1+R)+ \pm_{e ; t+1} P_{t+1}+{ }^{\circledR} H_{t+1}:
$$

The optimal demand for consumption and private health care of a type-e old agent at time $t+1$ are respectively ${ }^{6}$ :

$$
\begin{aligned}
& c_{e ; t+1}^{\text {at }}=" W_{e ; t+1}^{t} \\
& b_{e ; t+1}^{\text {at }}=(1 ; \quad) W_{e ; t+1}^{t} i \quad{ }^{t} H_{t+1}
\end{aligned}
$$

\footnotetext{
${ }^{6} \mathrm{Here}$, in order to ensure that $b_{\mathrm{e} ; \mathrm{t}+1}^{a \mathrm{t}}, 0$ 8e, we assume that even the individual with the lowest income has a non-negative demand for private health, i.e., that $\frac{e_{t}\left(1_{i} i t\right)(1+R)+ \pm_{e j t+1} P_{t+1}}{H_{t+1}}, \frac{\AA_{1 "}^{\prime \prime}}{1_{i}{ }^{m}}$ :
} 
Unsurprisingly, richer individuals are willing to supplement public health with more private health care. Moreover, in line with the ..ndings of Cutler and Gruber (1996), more public health care crowds out private health.

\subsection{The Welfare State}

Our welfare state consists of two instruments, which transfer resources across generations, from young (workers) to old agents (retirees): a public health program and a social security (or pension) system. At every timet, the young contribute a proportion, $i t$, of their income to the system, and every retiree is entitled to a lump sum one-time health care service, $H_{t}$, and receives a lump sum pension, $P_{t}$, for the remaining part of her old age, $\pm_{e ; t}$.

Notice that, although these systems are pay-as-you-go, i.e., current young ..nance the expenditure of current old, they both entail an element of intragenerational redistribution. In fact, both social security and public health care are ...nanced through a proportional tax, and thus place a higher burden on the medium-to-high income young, whereas the bene.ts, i.e., pension and medical service, are unrelated to income.

In our setting, agents are endowed with a young age income, and thus the income tax creates no distortion. To introduce a distortionary exect of taxation, and thereby to avoid agents to have too extreme preferences over the welfare state, we assume that there exists a quadratic cost of taxation?.

The welfare state is assumed to be balanced every period, so that its total expenditure in both programs has to be equal to the amount of collected taxed, $T_{t}$. Let, t be the share of collected taxes, $T_{t}$, dedicated to social security, and $(1 ;, t)$ to public health care. Then, accounting for the quadratic cost of taxation, we have that the total amount of collected taxes is:

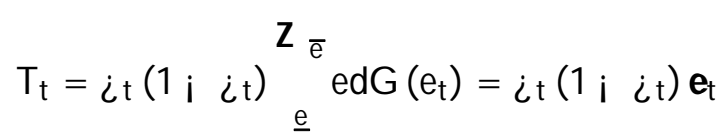

Notice that as the tax rate, ¿t, increases so does its distortionary exect. In particular, the maximum of the Laxer curve is reached for $i t=1=2$. Finally, the total amount of resources is divided between pensions:

$$
, \mathrm{T}_{\mathrm{t}}=\frac{e_{t} \mathrm{P}_{\mathrm{t}}}{\left(1+{ }^{\prime}\right)},
$$

where $P_{t}$ is the lump sum pension transfer paid to every retiree during her old age period, and public health care:

$$
(1 ;, t) T_{t}=\frac{H_{t}}{\left(1+{ }^{\prime}\right)} \text {. }
$$

Finally, to simplify the algebra, we assume that the upper bound on the public health expenditure, $\bar{H}$, is equal to the maximum amount of collectable taxes, i.e., $i=1=2$, entirely spent on health, i.e., $=0$, that is: $\bar{H}=\frac{1}{4}\left(1+{ }^{\prime}\right)$ e.

\footnotetext{
${ }^{7}$ W e choose this approach, rather than the more natural one - to endogenize the labor supply - because it allows us to obtain a close form solution of the voting game.
} 


\subsection{The Economic Equilibrium}

We can now de..ne the economic equilibrium as follows:

De..nition 2.1. For a given sequence of the tax rate and of the pension share, $f i t ;, t g_{t=0}^{1}$, and a given real interest rate, $R$, an economic equilibrium is a sequence of allocations,

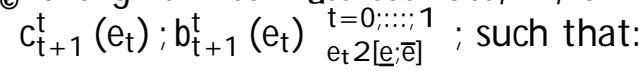

2 in every period, agents maximize their utility function at eq. 2.3 , with respect to $c_{t+1}^{t}(e)$ and $b_{t+1}^{t}(e)$, subject to the budget constraint in eq.2.5;

2 the welfare budget constraints are balanced every period, and thus equations 2.8, 2.9 and 2.10 are satis..ed; and

2 the goods market clears every period:

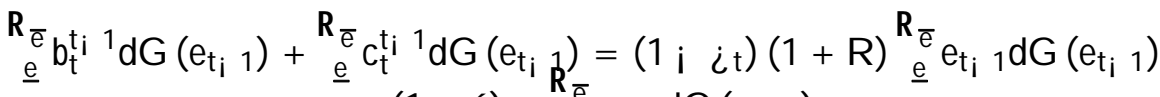

$$
\begin{aligned}
& +\left(1+{ }^{\prime}\right) \dot{i t} \underline{\underline{e}} e_{i_{i}} d G\left(e_{i} 1\right)
\end{aligned}
$$

The utility level obtained in an economic equilibrium by the agents is represented by their indirect utility functions. For a type-e young:

$$
v_{e, t}^{t}\left(i_{t} ; P_{t+1} ; H_{t+1} ; e_{t}\right)=\mu W_{e, t+1}^{t}
$$

where $\mu="$ " $(1 ; ")^{\left(1_{i} "\right)}$. It is now useful to substitute the welfare state budget constraints in the above expression, and to express the individual types, e, in terms of dixerences from the mean type e Thus, we obtain an indirect utility function for a type-E young that depends on current and future tax rates and on the future pension share:

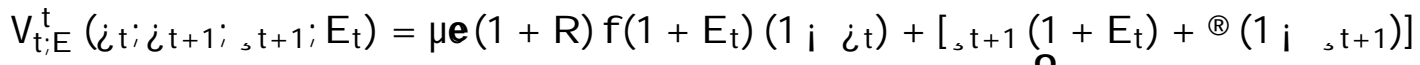

$$
\begin{aligned}
& \not(1+N) i_{t+1}\left(1 ; i_{t+1}\right) ; 4 E_{t, t+1}(1 ;, t+1) i_{t+1}^{2}(1 ; i t+1)^{2}
\end{aligned}
$$

where $(1+N)=\left(1+{ }^{\prime}\right)=(1+R)$ represents the relative performance of the social security system with respect to the private savings. For a type-E old individual at time the indirect utility function is:

$$
V_{t ; E}^{t_{i}{ }^{1}}\left(L_{t} 1 ; i t ;, t ; E_{t}\right)=V_{t_{i}}^{t_{i} 1 ; E}\left(i_{t} 1 ; i t ;, t ; E_{t}\right):
$$

\section{The Voting Game}

The size and the composition of the welfare state are decided by the agents through a political system of majoritarian voting. Elections take place every period, and all persons alive, young and old, cast a ballot over $i$, the income tax, and, the share of pension in the welfare state. Individual preferences over the two issues are represented by the indirect utility functions at equations 2.11 and 2.12, respectively for the young and the old. Notice that every agent has zero mass, and thus no individual vote could change the outcome of the election. To overcome this problem, individuals are assumed to vote sincerely.

This majoritarian voting game shares two important features with the games analyzed in Conde-Ruiz and Galasso (1999 and 2000). First, the issue space is bidimensional, 
$(i ;$,$) , and thus a Nash equilibrium may fail to exist, and second, the game is intrinsically$ dynamic, since it describes the interaction, or social contract, between successive generations of workers and retirees. We therefore use their concept of subgame perfect structure induced equilibrium ${ }^{8}$, which reduces the game to a dynamic issue-by-issue voting game.

Following their methodology, we ..rst analyze the case of full commitment, in which voters determine the constant sequence of the parameters of the welfare state $(i ;$,$) . In$ absence of a state variable, this voting game is static, and the result in Shepsle (1979) [T heorem 3.1] can be applied to obtain the suc cient conditions for a (structure induced) equilibrium to exist. In particular, if preferences are single-peaked along every dimension of the issue space, a suф cient condition for $\left(i^{a} ;,{ }^{\infty}\right)$ to be an equilibrium of the voting game with full commitment is that $i^{\alpha}$ represents the outcome of a majority voting over the jurisdiction $i$, when the other dimension is ..xed at its level ${ }^{\infty}$, and viceversa.

To use this theorem in our environment, we need to ensure that individuals' preferences are single peaked along the two dimensions, $i$ and, . The following lemma describes a set of suф cient conditions.

Lemma 3.1. Individuals' preferences are single-peaked over, for given ¿. Individuals' preferences are single-peaked over $i$ for given, if $E, \underline{E}=i \frac{,+\left(I_{i},\right)}{,\left(5 i, 4_{j}\right)}$ and $E \cdot 1$.

We therefore restrict the support of ability type of young and old individuals, in order to have that $E=(e ; e)=e 2[\underline{E} ; 1]$, that is e $2[e(1+\underline{E}) ; 2 e]$.

The second step to ..nd a subgame perfect structure induced equilibrium is to show that the (structure induced) equilibrium outcomes of the game with commitment are also subgame perfect equilibrium outcomes of the voting game without commitment ${ }^{9}$. In the game with no commitment, voters may only pin down the current values of $i$ and, although they may expect their current voting behavior to axect future voters' decisions. We will return to this point at the end of the next section.

\section{Politico-Economic Equilibria}

In this section, the individual votes over the each dimension of the issue space, $(i, j)$, are examined issue-by-issue. Initially, we assume that current voters can determine future policies, i.e., there exists commitment. Thus, voters cast a ballot over a constant sequence

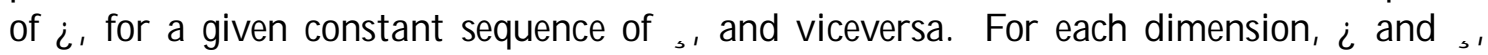
votes are then ordered to identify the median votes, which, by Shepsle (1979) theorem 3.1, represent the structure induced equilibrium outcome of the game with commitment. The results are then generalized to the game without commitment.

\subsection{Voting over the Size of the Welfare State}

R egardless of the composition of the welfare state, the elderly are net recipients from the system. Therefore, they will choose the tax rate that maximizes its size.

Lemma 4.1. For any share of pension in the welfare state, , the most preferred tax rate by any type-E old individual, $\sum_{E}^{O}$, is equal to $1=2$.

\footnotetext{
${ }^{8}$ See the appendix for a formal de..nition, and Conde-R uiz and Galasso (2000) for a detailed discussion.

${ }^{9} \mathrm{~A}$ full speci..cation of the voting game without commitment is in the Appendix.
} 
Today's young individuals may be willing to vote in favor of the welfare state, and thus to bear the cost of a current transfer, if their vote will also determine its future size, and thus their future bene..ts. In the game with commitment, a type-E young individual choose her vote, $\sum_{E}^{Y}$, by maximizing her indirect utility function at eq.2.11 with respect to a constant sequence of tax rates, $i_{t}=i_{t+1}=i_{E}^{Y}$. The next lemma characterizes the vote of the young.

Lemma 4.2. For a given share of pension, , the most preferred tax rate by any type-E young individual is positive, $\sum_{E}^{Y}>0$, if $E<E($,$) , and it is equal to zero, \sum_{E}^{Y}=0$, if $E$, $\mathrm{E}($,$) , where \mathrm{E}()=,\frac{\mathbb{Q}(1+N)\left(1_{i},\right)}{1_{i}(1+N)} ; 1$. Moreover, $\sum_{E}^{Y}$ is weakly decreasing in $E$ : $\frac{\mathfrak{Q}_{\mathrm{E}}^{\mathrm{Y}}}{\mathfrak{G E}} \cdot 0$.

Lemma 4.2 suggests that the political support to the welfare state relies heavily on its within-cohort redistribution component. While relatively high young types, E, E (, ), oppose the system, among the low-income young the preferred size of the welfare state is decreasing with the voter's types. Rich young individuals, $\mathrm{E}>0$, pay more taxes than the average, but receive the same public health expenditure and old age unitary pension as everybody else. Although they live longer, and thus enjoy a larger total pension transfer, this extra longevity is not suc cient to compensate for the higher contribution they make in youth. This result is strengthened if the public health share of the welfare expenditure is increased, since public health reduces the longevity dixerential among types, and thus the total pension of the wealthy. Also intermediate young types, $\left.\omega_{(},\right) \cdot E<0$, choose not to sustain the welfare state, despite receiving in old age more resources than they contribute in youth. In fact, the welfare state constitutes an ined cient technology to transfer resources into the future, and their young age contributions exceed the present value of their bene..ts. Only low-income young types, $E$. $E_{(}$, ), are net recipients ${ }^{10}$ and therefore vote for a positive welfare system, although they experience shorter longevity and thus enjoy smaller total pension transfers.

The next lemma constitutes an important step towards the our main result. It characterizes the relation between the size of the system chosen by a type $\mathrm{E}<\mathrm{E}($, ) young individual and the pension share, , and discusses the complementarity between the two welfare systems.

Lemma 4.3. The most preferred tax rate by any type-E young individual, with $\mathrm{E}<$ $\mathrm{E}($,$) , is weakly increasing for , .$, , and decreasing for,$>$, , where, ${ }^{0}=\frac{1}{2} \mathrm{i}$ $\frac{1+E_{i} \circledast}{16 E_{i}\left(1_{i} i\right)}<\frac{1}{2}$.

For,$=1$, the welfare state is a pure social security system. But the longevity of the low-income individuals, and thus their total pension bene..ts, is too low to induce them to support it. As part of the expenditure is devoted to health care, , $<1$, low-income agents experience an improvement in the quality of their life. Additionally, the longevity

\footnotetext{
${ }^{10} \mathrm{~N}$ otice that the mass of young voters in favor of the system, i.e., $\left.\mathrm{E} \cdot \mathrm{w}_{(}, \mathrm{)}\right)$, depends on the relative share of the two welfare programs, ,. While a pure social security system, $=1$, would receive no support, as the share of health care increases so does the mass of voters. The reason is that the low-income young greatly enjoy public health, which redistributes resources in their favor, and decreases the longevity dixerential.
} 
dixerential decreases, their total pension bene.ts begin to rise, and they are now willing to support the welfare state. Indeed, as the share of health care increases, their most preferred size of the welfare state rises because the existence of public health improves their total pension bene.ts. However, as the share of public health becomes too large, this complementarity between the two programs is reduced: the longevity dixerential keeps decreasing, but not enough to compensate the reduction in the unitary pension, and hence the agents choose to downsize the welfare state.

It is now straightforward to order all individuals' votes on the size of the welfare state, for a given pension share, and to identify the median voter's type. A gents can be ranked according to their age and type, as shown at ..gure 3, with elderly and then low-income young choosing larger sizes. The median voter is a type $E_{m_{i}}$ young agent who divides the electorate in halves: $G\left(E_{m_{i}}\right)={ }^{\prime}=2\left(1+{ }^{\prime}\right)$. For a given pension share, , we identify her most preferred tax rate as $\sum_{E_{m_{i}}}($,$) .$

\subsection{Voting over the Composition of the Welfare State}

When the issue at stake is the pension share, ,, for a given size of the system, $i$, votes only dixer according to the voters' type, and the voters' age plays no role. This is not surprising. In the game with commitment, today's decision will be in place tomorrow as well. And the composition of the welfare state is only relevant in old age, when the bene..ts from the two programs are received. Thus, a type-E young and a type-E old share the same voting decision: they choose their vote,, $\mathrm{E}$, by maximizing their indirect utility function at eq.2.11 and eq.2.12

Lemma 4.4. For a given tax rate, $i$, the most preferred social security share, ,E, by a type-E (young and old) individual is the following:

(i),$E=1$, if $E>0$;

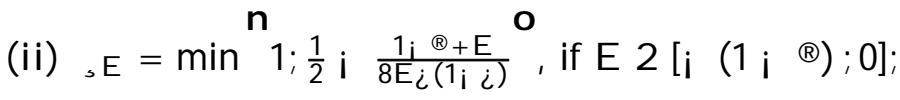

(iii), $E=\max { }^{n} 0 ; \frac{1}{2} i \frac{1_{i}{ }^{\circledR+E} E_{i}}{8 E_{i}\left(1_{i}\right)}$, if $E<i(1 ; ®)$.

Moreover,,$E$ is weakly increasing in $E$, i.e., $\frac{Q_{E}}{\sigma_{E}}, 0$. And, $E$ is weakly increasing in $i$ if $E \cdot i(1 ; \AA)$, and weakly decreasing in $i$ if $i(1 ; \AA)>E>0$.

Lemma 4.4 characterizes how the preferred composition of the welfare state depends on the individual type. Rich agents, whose type is above the mean, $E>0$, vote for a pure social security system, since public health reduces the longevity gap and increases the redistributive element of the system. Intermediate types (cases ii and iii) exploit the complementarity between the two programs, and hence favor a combination of the two, in order to increase their relative longevity and to receive an old age pension ${ }^{11}$.

$T$ he relation between the composition of the system chosen by a type- $E$ individual and its size, $\dot{i}$, depends on the voter's type. The votes of the high income types (case i) are unaxected by changes in the size. A mong the agents with intermediate types, the poorer

\footnotetext{
${ }^{11} N$ otice that for very small dimension, $i^{\prime} \quad 0$, preferences over the composition of the welfare state are extremely polarized: , $\mathrm{E}=0$ if $\mathrm{E} \cdot \mathrm{i}(1 \mathrm{i} \otimes)$, and, $\mathrm{E}=1$ if $\mathrm{E}>\mathrm{i}(1 ; \mathbb{i})$.
} 
(case iii) will respond to a rise in the size of the system with an increase of the pension share. In fact, a larger unitary pension compensates a lower longevity. Relatively richer agents (case ii), on the other hand, will trade ox a lower pensions for more public health.

Following the previous lemma, we can order the votes on the composition of the system according to the voters' types, as shown in ...gure 4 . The median voter is the low-income type, $E_{m}$, who divides the electorate in halves: $G\left(E_{m}\right)=1=2$. For a given size of the system, $i$, we identify her most preferred composition as, $E_{m},(i)$.

Figures 3 and 4 show a dixerent ordering along the two dimensions of the policy space. In fact, in deciding the size of the system, the age of the voters plays an important role, since the elderly favor the largest system, whereas only individual types matter in the composition. As a result, the median voter over the direction, has a higher type than the median voter over the dimension $i: E_{m},>E_{m_{i}}$.

\subsection{Characterization of Equilibria}

The previous sections have separately analyzed the voting behavior of all individuals along the two dimensions of the issue space, i.e., size and composition of the welfare state, under the assumption of commitment. Since preferences are single peaked, we can now apply Shepsle's (1979) result and characterize the structure induced equilibria of the game with commitment.

Proposition 4.5. There exists a structure induced equilibrium, $\left(i^{\alpha} ;,{ }^{\infty}\right)$, of the voting game with commitment, such that:

(A) $\left(i^{\alpha}=0 ;,{ }^{\alpha}=1\right)$ if $E_{m}, \quad i(1 ; \&)$ and $8 E_{m_{i}}$;

(B) $\left(i^{x}=0 ;,{ }^{\infty}=0\right)$ if $E_{m},<(1 ; ®)$ and $E_{m_{i}}$, E $($,$) ;$

(C) $\left(i^{\infty}>0 ;,{ }^{\infty}=0\right)$ if $E_{m},<i\left(1 ; @\right.$, and $-\left(E_{m},\right) \cdot E_{m_{i}}<E($,$) ;$

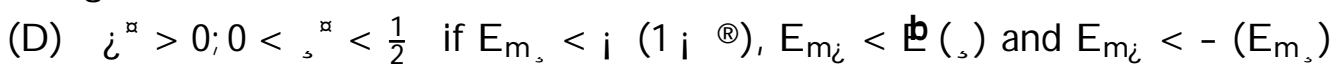

where $-\left(E_{m}\right)=i 1+\AA(1+N)^{p} \overline{i(1 ; ब) ~} \overline{E_{m}}$

If the median voter over, is suc ciently rich (case A), she will prefer a large share of pension, but then no young individual will be willing to support the system. If, on the other hand, the median voter over, prefers more health care, the size of the system will depend on the type of the median voter over $i, E_{m_{i}}$. The poorer the median voter, the larger the system will be. Moreover, a suф ciently poor median voter (case D), will exploit the complementarity between health care and social security, and hence will choose a larger system.

Notice that this proposition does not provide a complete characterization of the structure induced equilibria of the game. In fact, interior equilibria could arise in cases $A$ and $C$, if the reaction function $i^{\alpha}()=,\sum_{E_{m_{i}}}($,$) , which represents the decision of the median voter$ over $i$, becomes su $\not$ ciently steep, and crosses the reaction function, ${ }^{\alpha}(i)=, E_{m},(i)$, of the median voter over, as shown in ..gures 5 and 6 . Were these equilibria to exist, we would have a case of multiple equilibria. Even in this case, however, as we will discuss in section 6 , the main message of the paper would not be axected. 
W hat happens if we relax the assumption of commitment and consider a game in which voters may only determine the current size and composition of the welfare system? The result in proposition 4.5 generalize to a game without commitment:

Proposition 4.6. Every pair $\left(i^{x} ;,{ }^{\infty}\right)$, which constitutes a structure induced equilibrium of the voting game with commitment, is a (subgame perfect structure induced) equilibrium of the game without commitment.

The intuition is straightforward. Old agents' voting behavior does not depend on tomorrow's policy and thus on the existence of commitment. Low-income young individual, who were in favor of the welfare state in the case of commitment, will also be willing to enter an "implicit contract" among successive generations of voters to sustain the welfare state. This "implicit contract," or social norm, speci..es that if current young support the existing welfare system, they will be rewarded with a corresponding transfer of resources (pension and health care) in their old age, or they will be punished.

\section{Exogenous Longevity}

In order to analyze the impact of the political complementarity, which runs from health care to social security through the reduction in the longevity dixerential, on the size of the welfare system, we now examine the case of exogenous longevity. In this section, longevity is assumed to depend exclusively on the agent's type, and not to be axected by public health expenditure. At time $t$, a type-E individual enjoys the following longevity:

$$
\pm_{e ; t}^{x}=e_{t}\left(1+E_{t}\right)
$$

where the subscript $x$ indicates the variables in the exogenous longevity environment.

A gents solve the same economic problem as in section 2, and obtain the optimal demand of consumption and private health care at eq.2.7, where the wealth $\mathrm{W}_{\mathrm{e} ; \mathrm{t}+1}^{\mathrm{t}}$, previously de.ned at eq.2.6, will now depend on the exogenous longevity, $\pm_{e ; t}^{x}$, rather than on $\pm_{\text {e;t }}$. Notice that the only dixerence between the two cases lies in the total pension transfer, which, in the exogenous longevity case, depends entirely on the agent's type, whereas it is also axected by health care expenditure if longevity is endogenous.

The agents' preferences over the policy space $(i ;$,$) are again represented by the indirect$ utility function, which, for a type-E young at time $t$ is equal to:

$$
\begin{aligned}
& V_{t ; E}^{t ; x}\left(i_{t} ; i_{t+1} ; t+1 ; E_{t}\right)=\mu e(1+R) \\
& f\left(1+E_{t}\right)\left(1 ; \dot{L}_{t}\right)+\left[, t+1\left(1+E_{t}\right)+\circledast(1 ;, t+1)\right](1+N) i_{t+1}\left(1 ; \quad i_{t+1}\right) g
\end{aligned}
$$

and for a type-E old individual is:

$$
V_{t ; E}^{t_{i} 1 ; x}\left(i_{i} 1 ; i t ;, t ; E_{t}\right)=V_{t i}^{t_{i} 1 ; i x}\left(i_{t} 1 ; i t ;, t ; E_{t}\right):
$$

We can now turn to the agents' voting behavior. Following the methodology explained in section 3, we ..rst analyze the voting game with commitment, and then generalize the results to the game without commitment. 


\subsection{Voting over $i$ and,}

For any composition of the welfare state, a type-E old agent will vote $\sum_{E}^{O ; x}=1=2$, in order to maximize the size of the system, from which, as in the previous case, she is a net recipient.. A type-E young individual may bene.tt from the welfare state depending on her type. For a given pension share, she will choose the tax rate, $\dot{L}_{E}^{Y ; x}$, which maximizes her indirect utility at eq.5.2.

Lemma 5.1. For a given share of pension, , the most preferred tax rate by any type-E young individual, $\dot{L}_{E}^{Y ; x}$, is the following:

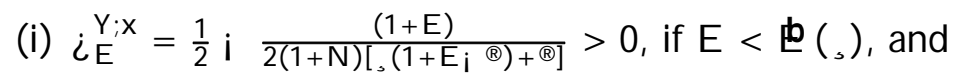

(ii) $\dot{L}_{E}^{Y ; x}=0$, if $E$,

Moreover, $\sum_{E}^{Y ; x}$ is weakly decreasing in $E$ and in, , $\frac{\varrho_{E}^{Y ; x}}{\varrho_{E}} \cdot 0$ and $\frac{\varrho_{E}^{Y ; x}}{\bigotimes_{s}} \cdot 0$.

A s in the previous case, relatively rich young agents, $E$, $巴($, ), will oppose the welfare state, $\dot{L}_{E}^{Y ; x}=0$. Low-income young choose a positive tax rate, which is larger the lower the voter's type. These agents enjoy a lower than average longevity, and thus prefer health care to social security, since health care provides a one-time old age bene..t, whereas social security pays an annuity. Additionally, health care does not improve their longevity, and thus their most preferred tax rate decreases as the share of pension increases. In the extreme case of a pure social security system, the size would be zero.

The ordering of the votes over $\dot{i}$, and thus the median voter, $E_{m_{i}}^{x}$, is the same as in the endogenous longevity case: $E_{m_{i}}^{x}=E_{m_{i}}$ (see ..gure 3).

$W$ hen voting over the composition of the system, , the only relevant characteristic of the agent is their type. For a given size, $\dot{i}$, a type-E young and old individual choose the same pension share,, $\mathrm{E}$.

Lemma 5.2. For any tax rate, $i$, a type-E (young and old) individual prefers a pure health care system,,$\underset{E}{X}=0$, if $E \cdot i(1 ; \mathbb{i})$, and a pure social security system,,$\underset{E}{X}=1$, if $E>i(1 ; @)$.

Since health care does not axect the longevity dixerential, and thus the relative return on social security, the voting behavior becomes more polarized. Relatively rich individuals livelonger, and favor a pure social security system, since the bene..ts from the total pension transfer, $1+E$, exceeds the bene.ts from public health care, ${ }^{\circledR}$ T he opposite is true for poorer individuals, $\mathrm{E} \cdot \mathrm{i}(1 \mathrm{i} \mathbb{R})$. Votes over the dimension, can easily be ordered in two groups, according to the voters' type. Finally, notice that the median voter's type, $\mathrm{E}_{\mathrm{m}}^{\mathrm{x}}$, coincides with the median voter in the case of endogenous longevity, $\mathrm{E}_{\mathrm{m}}$.

\subsection{Characterization of Equilibria}

A pplying Shesple's (1979) result to the voting game with commitment, we can characterize the structure induced equilibria as follows. 
Proposition 5.3. There exists a structure induced equilibrium, $\left(i_{x}^{\alpha} ;, x\right)$, of the voting game with commitment, such that:
(A) $\left(i_{x}^{\alpha}=0 ;, \underset{x}{\alpha}=1\right)$ if $E_{m}, i(1 ; @)$ and $8 E_{m_{i}}$;
(B) $\left(i_{x}^{\infty}=0 ;, x=0\right)$ if $E_{m},<i(1 ; ®)$ and $E_{m_{i}}$, E $($,$) ;$
(C) $\left(i_{x}^{a}>0 ;, x=0\right)$ if $E_{m},<(1 ; @)$ and $E_{m_{i}}<{ }^{\infty}($,$) .$

A s in the previous section, the existence of a welfare state, $i>0$, requires both median voters to be relatively poor. However, in this case, the welfare state may only consist of a pure health care system. In fact, in absence of the exect of public health on the longevity dixerential, a pension system is never sustained because of the lack of support by the lowincome young. As in the case of endogenous longevity, these structure induced equilibrium outcomes can easily be generalized, in a game without commitment, to subgame perfect structure induced equilibrium outcomes.

\section{Comparing Equilibria}

We can now compare the equilibria obtained in the previous sections under the hypothesis of endogenous and exogenous longevity. For a given distribution of income, and therefore of initial health status, we aim at isolating the impact of the political complementarity on the size of the welfare system. In particular, we want to characterize the speci..c exect on the dimension of the welfare of the reduction in the longevity dixerential induced by the public health expenditure. The results are summarized in the following proposition.

Proposition 6.1. If $E_{m}, z \alpha$, the welfare state, i.e., the equilibrium tax rate, is weakly larger in the case of endogenous longevity. In particular:

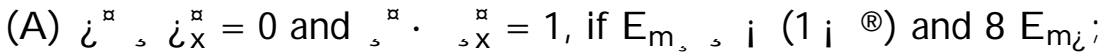

(B) $i^{x}=i_{x}^{\alpha}=0$ and,${ }^{x}=, x=0$, if $E_{m},<i(1 ; \&)$ and $E_{m_{i}}, E_{y}^{0}($,$) ;$

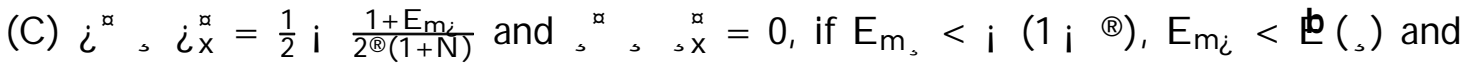
$E_{m_{i}}$, - $\left(E_{m_{0}}\right)$;

(D) $i^{\not}>i_{x}^{\alpha}$ and,${ }^{\infty}>, x=0$, if $E_{m},<i(1 ; ®), E_{m},<\tilde{A}\left(E_{m_{i}}\right), E_{m_{i}}<\notin($,$) , and$ $E_{m_{i}}<-\left(E_{m_{j}}\right)$,

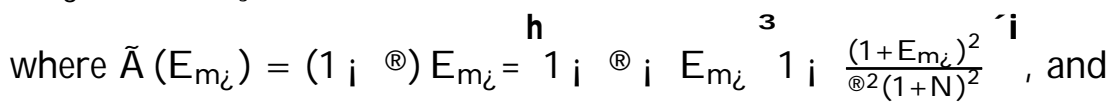

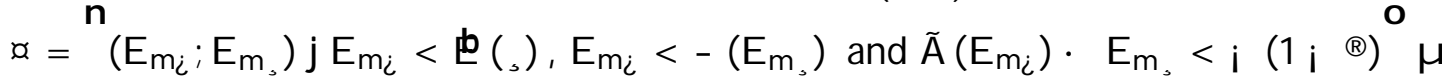

$[\underline{E} ; 1] f[\underline{E} ; 1]$

In the ..rst three cases, the equilibrium size of the welfare state is not axected by the assumption on the longevity, except if multiple equilibria arise. In case (A), a relatively rich median voter over, chooses a pure social security system, which no young individual is willing to sustain. Here, the inequality may arise in the rather unrealistic 
situation, described in ..gure 5 , in which the median voter over $i$ is extremely poor, and the complementarity between the two programs is strong enough even for large values of .. In case (B), the median voter over $i$ is a relatively high-income type, who opposes the welfare state, $i=0$. In case $C$, a low-income median voter over, prefers a pure health care system. The median voter over $i$ is relatively rich. She does not bene.t from the complementarity between the two programs, and hence votes the same tax rate as in the exogenous longevity case. Here, the inequality may again arise if there are multiple equilibria as shown in ..gure 6.

Case (D) is the most interesting one. The political complementarity between social security and health care arises, and hence the welfare state is larger with endogenous than with exogenous longevity. Let's see why. The median voter over $i$ is a low-income type. Due to her low longevity, she tends to favor health care. However, as shown in Lemma 4.3, when public health expenditure is very large, she bene..ts from an increase in the pension share, since the loss in longevity is compensated by an increase in pension bene.ts. In this case, she will respond to a rise in the pension share with a corresponding increase in the size of the system, until a certain threshold, , is reached. A fter this pension share, the size of the system would be reduced. The median voter over, is a low type too, and thus prefers a composition of the welfare state more oriented towards public health care. Moreover, since $E_{m},<i(1 ; \AA)$, by Lemma 4.4 , the median voter responds to an increase in the dimension of the system with a rise in the pension share. The sud cient condition, $E_{m},<\tilde{A}\left(E_{m_{i}}\right)$, guarantees that the median voter over, has a suф ciently low income, and hence prefers more health care. As a result, she will not push the composition of the welfare state so far towards social security as to induce the median voter over $i$ to downsize the system. Therefore, the complementarity between the programs is preserved, and the welfare state is larger under endogenous than under exogenous longevity.

Figure 7 summarizes the restrictions imposed on the ability types of the individuals, and characterizes the equilibria under endogenous and exogenous longevity for dixerent combinations of the median voters' types. A rea I represents case (C) in proposition 6.1: the dimension of the welfare state is typically unarected by the longevity type. A rea II corresponds to case (D): the median voter over, has suc ciently low type to keep the composition of the welfare state towards more public health, and thus to guarantee the existence of political complementarity. In area III, on the other hand, the comparison between endogenous and exogenous longevity is ambiguous, since the median voter over is relatively rich, and may push the welfare state towards too much social security, thereby inducing its size to be reduced, by the median voter over $\dot{i}$, even below the level of exogenous longevity.

\section{Conclusion}

Public opinion and policymakers have become increasingly concerned with the rise in public health and social security expenditure. Since both programs generate a $\neq$ ow of resources from the workers to the retirees, the major suspect in explaining this increasing trend is the aging process. However, demographic dynamics may only be held partially responsible for this rise in health care and social security expenditure. The number of recipients from these programs, the elderly, has certainly increased, but so has done the per capita resources that they have received, particularly in health care. 
We suggest that some political features of these two programs may be responsible for a multiplicative exect, which enlarges the impact of the aging process. Health care and social security are political complements in that the existence of health care increases the political support in favor of social security, and viceversa. Philipson and Becker (1998) emphasize the link from social security to public health. The existence of an annuity, the old age pension, increases the value of longevity and, hence, increases the demand for public health.

We focus on the opposite direction, from public health to social security. We argue that public health reduces the longevity dixerential between low and high-income agents, and hence allows low-income individuals to enjoy larger retirement periods, relatively to high-income agents. This exect fosters the with-in cohort redistributive component of social security, and increases the political support to this program among the low-income individuals. In a two-dimensional voting model, in which voters determine the size and the composition of the welfare state, we show that this political complementarity leads to the adoption of a large welfare system, in which the public health component is large, relatively to social security. 


\section{A. A ppendix}

\section{Lemma 3.1}

To prove that the preferences of every agent are single peaked over each dimension, $i$ and, it is suc cient to show that her indirect utility function is quasi concave over each dimension.

Consider ..rst the dimension, for a given $i$. For a type-E agent, the second derivative w.r.t. of her indirect utility function, eq. 2.11 , is $8 \mathrm{eE} i^{2}(1 \mathrm{i} i)^{2}$. Since e $>0$, preferences are clearly single peaked if $E \cdot 0$. For $E>0$, the indirect utility function is convex. However, since the ..rst derivative w.r.t., evaluated in, $=0$ is positive, these agents simply prefer higher, to lower, and preferences are still single peaked, with a maximum in, $=1$.

Consider now the dimension $i$ for a given,. For a type-E old agent, the second derivative w.r.t. $i$ of her indirect utility function, eq. 2.12 , is

$$
\operatorname{SOC}_{E}^{O}(i)=2^{n} i,(1+E) i \circledast(1 ;,) i 4 E,(1 ;,)^{3} 1 i 6 i+6 i^{2} \text { : }
$$

Notice that 1 i $6 i+6 i^{2}, 0$ for $i \cdot i_{1}=\frac{1}{2} i \quad{ }_{\frac{1}{6}} \mathrm{p} \overline{3}$ and $i, \quad i 2=\frac{1}{2}+\frac{1}{6} \mathrm{p}_{\overline{3}}$. Thus, it is easy to see that for $E, 0$ and $i \cdot i_{1}$ or $i, i_{2}$, and for $E \cdot 0$ and $i_{1} \cdot i \cdot i_{2}$, then $\operatorname{SOC}_{E}^{O}(i) \cdot 0$. For $E>0$ and $i_{1} \cdot i \cdot i 2$, the last term in the $\operatorname{SOC}_{E}^{O}(i)$ is positive. This term is maximum for $i=1=2$, thus if $\operatorname{SOC}_{E}^{O}(i=1=2)<0$ ! $\operatorname{SOC}_{E}^{O}(i)<08 i$. It is straightforward to see that $\operatorname{SOC}_{\mathrm{E}}^{O}(i=1=2)<0$ if $\mathrm{E} \cdot \frac{,+\mathbb{R}\left(1_{\mathrm{i}},\right)}{\left(1_{\mathrm{i}} 2_{j}\right)}>1$. Finally, the last term in the $\operatorname{SOC}_{\mathrm{E}}^{O}(i)$ is also positive for $\mathrm{E}<0$ and $i \cdot i_{1}$ or $i, i 2$, and is largest for $i=0$ or $i=1$. Thus if $\operatorname{SOC}_{\mathrm{E}}^{O}(i=0)<0 ! \operatorname{SOC}_{\mathrm{E}}^{O}(i)<08 i$. It is easy to see that $\operatorname{SOC}_{E}^{O}(i=0)<0$ if $E>\underline{E}=i \frac{,+\mathbb{B}\left(1_{i},\right)}{(5 i 4)}$.

For a type-E young agent, the second derivative w.r.t., of her indirect utility function is the same as for a type-E old agent, except for a multiplicative constant, $1+N$, and thus the same restrictions apply, which proves the lemma.

Voting Game without Commitment

We consider that voters can only determine current size and composition of the welfare state, although they may expect their vote to condition future voters' decisions. We de..ne the voting game with no commitment as follows.

The sequence of tax rates and pension shares until $t_{i} 1$ constitutes the public history of the game at time $t, h_{t}=f\left(\Sigma_{0} ;, 0\right) ; \ldots: ;\left(\Sigma_{t}, 1 ;, t_{i} 1\right) g 2 X_{t}$, where $X_{t}$ is the set of all possible history at time t.

A $n$ action for a type $E$ young individual at time $t$ is a pair of tax rates and pension

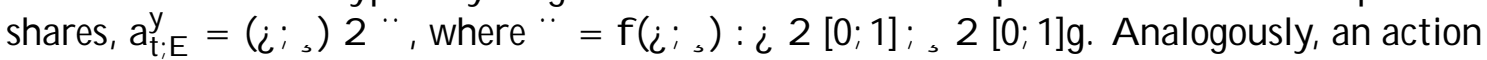
for a type $\mathrm{E}$ old individual at time $\mathrm{t}$ is $\mathrm{a}_{\mathrm{t} ; \mathrm{E}}^{\mathrm{O}}=\left(i ;,{ }_{,} 2{ }^{\prime}\right.$. We call $a_{\mathrm{t}}$ the action pro..le of all individuals (young and old) at time $t: a_{t}=\left(a_{t}^{y}\left[a_{t}^{o}\right)\right.$ where $a_{t}^{y}={ }_{E 2[E ; 1]}\left[a_{t ; E}^{y}\right.$ and $a_{\mathrm{t}}^{0}={ }_{\mathrm{E} 2[\mathrm{E} ; 1]} a_{\mathrm{t} ; \mathrm{E}}^{\mathrm{o}}$.

For a type $E$ young individual a strategy at time $t$ is a mapping from the history of the game into the action space: $s_{t ; E}^{y}: h_{t} !{ }^{\prime \prime}$, and analogously for a type $E$ old individual at time t: $\mathrm{S}_{\mathrm{t} ; \mathrm{E}}^{\mathrm{O}}: \mathrm{h}_{\mathrm{t}}$ ! " . The strategy pro..le played by all individuals at time $\mathrm{t}$ is denoted

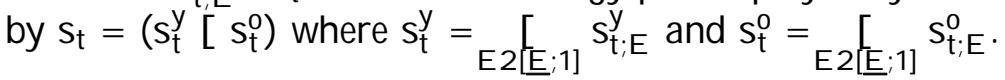


At time $t$, for a given action pro..le, $a_{t}$, the pair $\left(i_{t}^{m} ;, t\right)$ represents the medians of the distributions of tax rates. We take $\left(i_{t}^{\mathrm{m}} ;, \mathrm{m}\right)$ to be the outcome function of the voting game at time $t$. This outcome function corresponds to the structure induced equilibrium outcome of the voting game with commitment, according to Shepsle' (1979) results. The history of the game is updated according to the outcome function; at time $t+1: h_{t+1}=$ $\mathrm{f}\left(i_{0} ;, 0\right) ;:: ;\left(i_{\mathrm{t} i} 1 ;, \mathrm{t}_{i}\right) ;\left(i_{\mathrm{t}}^{\mathrm{m}} ; \mathrm{t}, \mathrm{m}\right) \mathrm{g} 2 \mathrm{X}_{\mathrm{t}+1}$.

For every agent, the payou function corresponds to her indirect utility. Formally, for a given sequence of action pro..les, $\left(a_{0} ; \ldots ; a_{t} ; a_{t+1} ;:::\right)$, and of corresponding realizations, $\left(\left(\Sigma_{0} ;, 0\right) ;: .: ;\left(\Sigma_{t} ;, t\right) ;\left(\Sigma_{t+1} ;, t+1\right) ;:::\right)$, the payou function for a type $E$ young individual at time $t$ is $V_{t ; E}^{t}\left(i t ; i t+1 ;, t+1 ; E_{t}\right)$, as de..ned in eq. 2.11, and for a type $E$ old agent is $V_{t ; E}^{t_{i}}{ }^{1}\left(i_{i} 1 ; i t ;, t ; E_{t}\right)$, according to eq. 2.12.

Let $\mathrm{s}_{\mathrm{t}}^{\mathrm{y}} \mathrm{x}_{\mathrm{w}}=\mathrm{s}_{\mathrm{t}}^{\mathrm{y}}=\mathrm{s}_{\mathrm{t} ; \mathrm{w}}^{\mathrm{y}}$ be the strategy pro..le at time $\mathrm{t}$ for all young individuals except

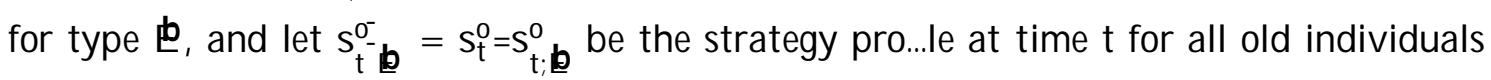
except for the type $\mathbb{E}^{\mathrm{W}}$. Then, at time $\mathrm{t}$, a type $\mathrm{E}^{\mathrm{E}}$ young individual maximizes

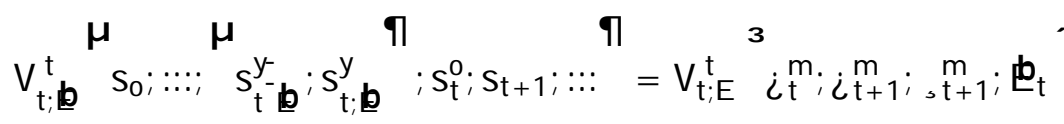

and a type $\mathrm{E}^{\mathrm{O}}$ old individual maximizes

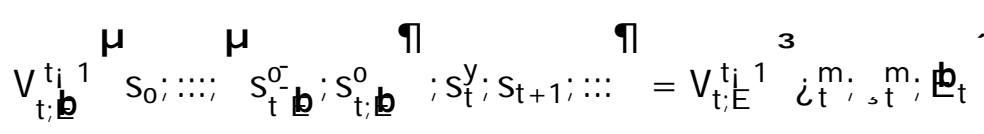

where, according to our previous de. nition of the outcome function, $\left(\dot{\alpha}_{t}^{m} ;, t\right)$ and ${ }^{i} \dot{i}_{t+1}^{m} ;{ }_{t+1}^{m}{ }^{\phi}$ are, respectively, the medians among the actions over the size and composition of the welfare state played at time $t$ and $t+1$.

As previously argued, to deal with the two-dimensionality of the issue space, and to allow for intergenerational implicit contracts to arise, our equilibrium concept combines subgame perfection with the notion of structure induced equilibrium. We can now de..ne a subgame perfect structure induced equilibrium of the voting game as follows:

De..nition A.1 (SPSIE). A voting strategy pro..le $s=f\left(s_{t}^{y}\left[S_{t}^{o}\right) g_{t=0}^{1}\right.$ is a Subgame Perfect Structure Induced Equilibrium (SPSIE) if the following conditions are satis..ed:

$2 \mathrm{~s}$ is a subgame perfect equilibrium.

2 At every time t, the equilibrium outcome associated to $s$ is a Structure Induced Equilibrium of the static game with commitment.

Lemma 4.1

Trivial. For $\mathrm{E} 2[\underline{\mathrm{E}} ; 1]$, the indirect utility function at eq.2.12 is concave w.r.t. $i$, and is maximized at $i=1=2$.

Lemma 4.2

Notice that the ..rst order condition over $i$ in the optimization problem of a type-E young voter is equal to the ..rst order condition of a type-E old voter decreased by $1+E$, i.e., $F_{E C}^{Y}(i)=F_{E} O_{E}^{O}(i)$ i $(1+E)$. By Lemma 3.1, since $E 2[\underline{E} ; 1]$, the indirect 
utility function is concave over $\dot{i}$, and thus a suc cient condition for a type-E young voter to maximize her indirect utility function in an interior, i.e., for $i>0$, is that the ..rst order condition, evaluated at $i=0$, is strictly positive, $\mathrm{FOC}_{\mathrm{E}}^{Y}(i=0)>0$. It is easy to see that if $E<E()=,\frac{\circledR(1+N)\left(1_{i},\right)}{1_{i}(1+N),}$ i 1 , then $F_{E} O_{E}^{Y}(i=0)>0$.

Finally, to prove that $\frac{Q_{E}^{Y}}{(E} \cdot 0$, notice that for $E>E($,$) then \sum_{E}^{Y}=0$, and $\frac{Q_{E}^{Y}}{\Phi}=0$. To examine the other case, $E$. $E\left(\right.$, ), we dixerentiate the $F O_{E}^{Y}(i)$ w.r.t. $\sum_{3}^{Y}$ and $E$,

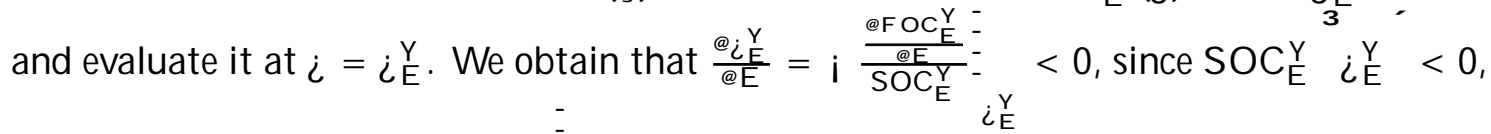

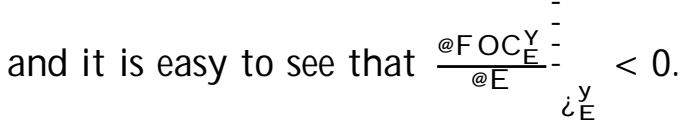

Lemma 4.3

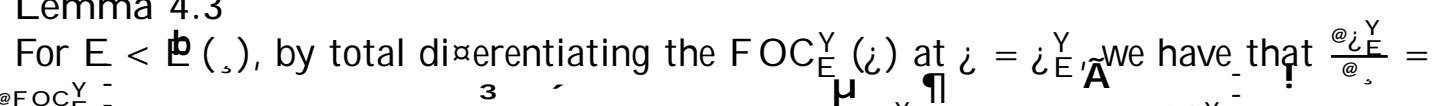

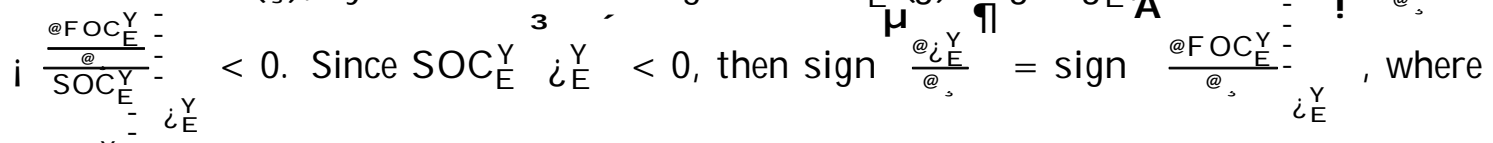

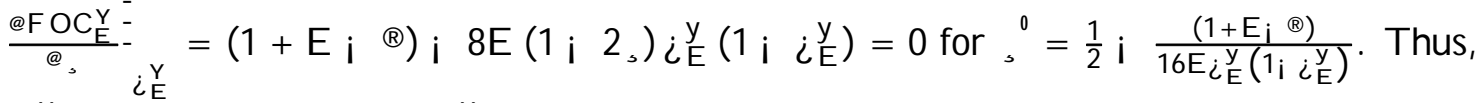

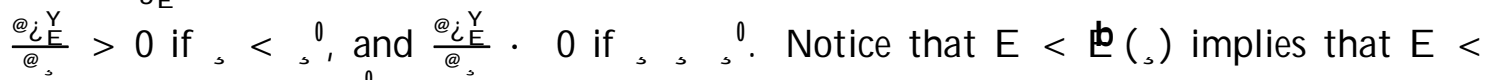
i $(1$ i $\mathbb{R})$, and thus, ${ }^{0}<1=2$.

Lemma 4.4

Case (i) follows from lemma 3.1: recall that for $E>0, F_{E}(,=0)>0$ and $\operatorname{SOC}_{E}()>$,0 . Case (iv): for $E \cdot i \frac{1_{j} \circledast}{1+4_{i}\left(1_{i} i \beta^{\prime}\right.}, F C_{E}(,=0) \cdot 0$ and $\operatorname{SOC}_{E}()<$,0 ,

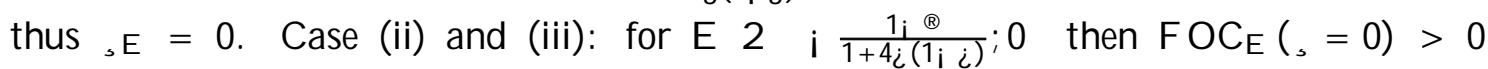
and $\operatorname{SOC}_{E}()<$,0 . The intermediate cases may arise, since $\mathrm{FOC}_{E}(, \mathrm{E})=0$ for, $\mathrm{E}=$

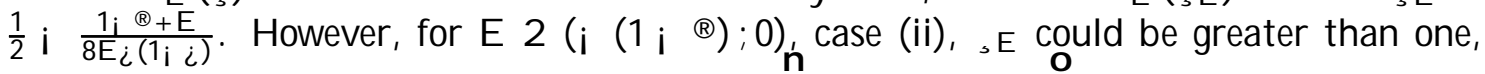
and thus we need to impose that, ${ }_{3}=\min \frac{1}{2} \mathrm{i} \frac{1_{\mathrm{i}}{ }_{\mathrm{B}} \mathrm{B}+\mathrm{E}}{8 \mathrm{E}_{i}\left(1_{\mathrm{i}}\right)} ; 1$. Analogously, for $E 2$

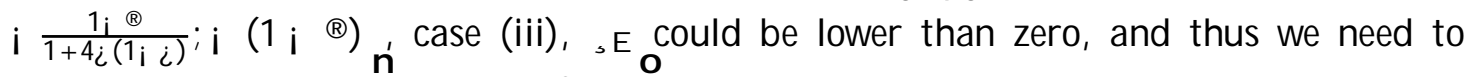
impose that, $\mathrm{E}=\max 0 ; \frac{1}{2} \mathrm{i} \frac{1_{\mathrm{i}} \otimes+\mathrm{E}}{8 \mathrm{E} i\left(1_{\mathrm{i} i}\right)} \mathrm{O}$.

Moreover, it is straightforward to see that $\frac{\varrho_{E}}{G_{E}}>0$ for , E $2(0 ; 1)$

and $\frac{Q_{E}}{\Phi_{E}}=0$ for,$E=f 0 ; 1 g$. Finally, $\frac{Q_{E}}{Q_{Q}}=\frac{\left(1_{i} \otimes+E\right)\left(1_{i} 2_{i}\right)}{8 E i^{2}\left(1_{i} i\right)^{2}}$, which is non-negative for $E \cdot i(1 ; \AA)$, and negative for $0>E>i(1 ; \AA)$.

\section{P roposition 4.5}

By Shepsle's (1979) Theorem 3.1, a structured induced equilibrium is a pair $\left(i^{a} ;,{ }^{\alpha}\right)$, in which $i^{x}$ is the median vote over the dimension $\dot{i}$, when the other dimension is ..xed at the level,$"$, and, is the median vote over the dimension, , when the other dimension is ..xed at the level $i^{\star}$. We have previously identi..ed the median voters, respectively over the dimension $i$ and, with a type- $E_{m_{i}}$ young and a type- $E_{m}$, (young or old) individual. Since the ordering of the votes over one dimension, e.g., $\dot{L}$, is not axected by the value of the other dimension, e.g., , , the median vote over $i$ and, always coincides with the votes of a type- $E_{m_{i}}$ young and a type- $E_{m}$, (young or old) individual. We can now analyze the dixerent cases. 
Case $(A)$ is trivial. If $E_{m}, i(1 ; \&)$, then, ${ }^{\infty}=1$, and for, $=1, i^{\infty}=08 E_{m_{i}}$.

Case (B) is trivial too. If $E_{m_{i}}$, $E^{b}($,$) , then i^{\infty}=0$, and for $i^{\infty}=0$, if $E_{m},<i(1 ; ®)$, then, ${ }^{\infty}=0$.

Case $(C)$ : If $E_{m}<i \quad\left(1 ;{ }^{\circledR}\right)_{n}$ the median voter will vote according to Lemma 4.4, case $i \mathrm{ii}$ and thus, $E_{m},(i)=\max 0 ; \frac{1}{2} i \frac{l_{i} \otimes+E_{m}}{8 E_{m} i\left(1_{i} i\right)}$, or case iv and thus, $E_{m},(i)=0$. If $E_{m_{i}}<\notin($,$) , then i E_{m_{i}}()>$,0 . Notice that for, $=0, i E_{m_{i}}(0)=\frac{1}{2} i \frac{1+E_{m_{i}}}{2 \Theta(1+N)}$. In order to have a structure induced equilibrium at $\left(i^{\alpha}=\sum_{E_{m_{i}}}(0)>0 ;,{ }^{\infty}=0\right)$, we thus need to have that $, E_{m},=0$ for $i E_{m_{i}}=\frac{1}{2} i \frac{1+E_{m}}{2 ब(1+N)}$. By substituting this value of $i E_{m_{i}}$ in $, E_{m},(i)$ at Lemma 4.4, case iii, it easy to see that, $E_{m},=0$, if $E_{m_{i}},-\left(E_{m_{0}}\right)=$ i $1+\AA(1+N) \overline{\text { i }(1 ; \AA)=E_{m} \text {. }}$.

Case (D): If $E_{m_{1}}<i(1 ; \AA)$ and $E_{m_{i}}<E($,$) , as in case C$, but $E_{m_{i}}<-\left(E_{m_{1}}\right)$, there is no equilibrium at, ${ }^{\prime}=0$, since ${ } E_{m_{i}}(,=0)$ is greater than the maximum $i$ such that $, E_{m},(i)=0$. In other words, at,$=0$, the reaction function $i E_{m_{i}}($,$) , which$

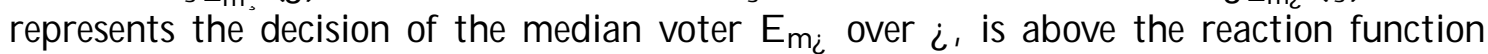
$, E_{m},(\Sigma)$, which represents the decision of the median voter $E_{m}$, over . Notice that $i_{E_{m_{i}}}($,$) is continuous and bounded above by 1=2$, whereas by lemma $4.4, \ldots E_{m},(i)$ is continuous and weekly increasing in $i$ for $E_{m},<i(1 ; ®)$. Therefore, the two reaction functions will cross in a point $\left(i^{\infty}>0 ; 0<,,^{\infty}<1=2\right)$, which constitutes a Sl equilibrium since $\dot{L}_{\mathrm{m}_{i}}\left({ }^{\infty}\right)=i^{\infty}$ and, $E_{m},\left(i^{\infty}\right)=,{ }^{\infty}$.

Proposition 4.6

Suppose $\left(i^{\alpha_{2}},{ }^{\infty}\right)$ is a structure induced equilibrium outcome of the voting game with commitment. Let us de. ne the following realization of the public history of the game:

$$
X_{t}^{0}=f h_{t} 2 X_{t} j i_{k}=0 ; k=0 ; \ldots ; t ; 1 g
$$

and

$$
X_{t}^{i}=f h_{t} 2 X_{t} j 9 t_{0} 2 f 0 ; 1 ;:: ; t ; 1 g: t_{t}=08 t<t_{0} \text { and }, t=, 8 t, t_{0} g
$$

notice that $\mathrm{X}_{\mathrm{t}}^{0} \backslash \mathrm{X}_{\mathrm{t}}^{\mathrm{i}}=$;

Consider the following strategy $s=s_{t ; E}^{\mathrm{y}} ; \mathrm{s}_{\mathrm{t} ; \mathrm{E}}^{\mathrm{O}}$, for a type $\mathrm{E}$ young:

i) if $E \cdot E_{m_{i}}$

$$
s_{t ; E}^{y}=\begin{array}{ccc}
\left(i^{a} ;, t ; E\left(i^{a}\right)\right) & \text { if } & h_{t} 2 X_{d y}^{0}\left[X_{t}^{i}{ }_{t}^{a}\right. \\
(0 ;, t ; E(0)) & \text { if } & h_{t} 2 X_{t}=X_{t}^{0}\left[X_{t}^{i^{2}}\right.
\end{array}
$$

ii) if $E>E_{m_{i}}$



and for a type-E old individual

$$
\mathrm{S}_{\mathrm{t} ; \mathrm{E}}^{\mathrm{O}}=\left(1=2 ;, \mathrm{t} ; \mathrm{E}\left(i^{\circledR}\right)\right) \text { if } \mathrm{h}_{\mathrm{t}} 2 \mathrm{X}_{\mathrm{t}}
$$

where $\dot{L}_{t ; E}^{Y}\left(,{ }^{\infty}\right)$ is de.ned in Lemma 4.2, and, t;E $\left(i^{\ltimes}\right)$ in Lemma 4.4. 
Since by de..nition of $\operatorname{SIE}, \dot{i}^{\alpha}=i t ; E_{m_{i}}\left({ }^{\alpha}\right)$ and,$^{\alpha}=, t ; E_{m},\left(i^{\alpha}\right)$, it is easy to see that:

$$
\begin{aligned}
& i t ; E_{m_{i}}\left(,{ }^{\infty}\right), \quad i^{\infty} 8 E \cdot E_{m_{i}}, \\
& , t ; E_{m},\left(i^{\infty}\right), \quad, 8 E \cdot E_{m},
\end{aligned}
$$

Recall that the outcome function of the voting game at time $t$ is the median in every dimension of the distribution ${ }_{3}$ of actions, $\left(\sum_{t}{ }_{i}, t, t\right)$, then it is straightforward to see that the previous strategy pro..le $\mathrm{s}_{\mathrm{t} ; \mathrm{E}}^{\mathrm{y}} ; \mathrm{s}_{\mathrm{t} ; \mathrm{E}}^{\mathrm{O}}$ constitute a subgame perfect equilibrium of the voting game with no commitment, with equilibrium outcome $\left(i^{\alpha} ;,{ }^{\infty}\right)$.

\section{Lemma 5.1}

First notice that young agents' preferences over $i$ are single peaked, since the indirect utility function at eq. 5.2 in concave in $i$. This function has a maximum at $i=\frac{1}{2} \mathrm{i}$

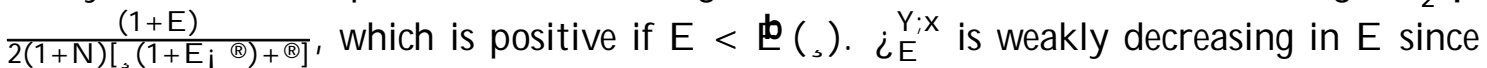

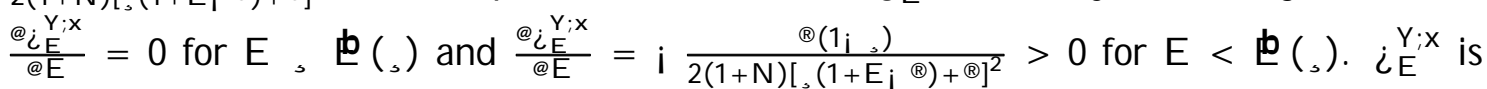

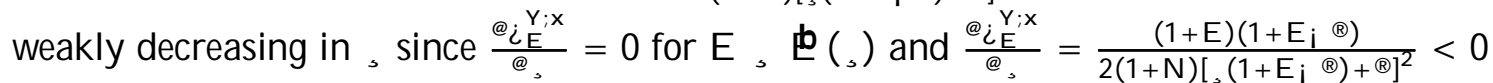
for $E<\mathrm{E}($,$) , because E<\mathrm{E}($,$) implies E<\mathrm{i}(1 \mathrm{i} \circledast$ )

\section{Lemma 5.2}

Trivial. From the indirect utility functions at eq. 5.2 and 5.3, we have that $\mathrm{FOC}_{\mathrm{E}}\left({ }_{2}\right)=$ $\mu \mathbf{e}(1+R)(1 ; @+E)$, and $\operatorname{SOC}_{E}()=$,0 . Thus,,$\underset{E}{X}=0$ if $E \cdot i(1 ; ®)$, and,$\quad x=1$ if $E>i(1 ; @)$. Notice that if $E=i(1 ; @)$, the agent is indixerent between, ${ }_{E}=0$ and ,$\underset{E}{X}=1$. We break the indixerence in favor of,$\underset{E}{X}=0$.

\section{Proposition 5.3}

As in Proposition 4.5, we apply Shepsle's (1979) Theorem 3.1. All cases are trivial. Case $(A)$ : if $E_{m}, i\left(1 ; \mathbb{i}\right.$, then $\underset{x}{x}=1$, and for, $=1, i_{x}^{\alpha}=08 E_{m_{i}}$. Case $(B)$ and $(C)$ : if $E_{m},<i(1 ; \AA)$, then,$x=0$. For,$x=0$, if $E_{m_{i}}$, $E^{x}($,$) , then i_{x}^{\alpha}=0$ (case $(B)$ ),

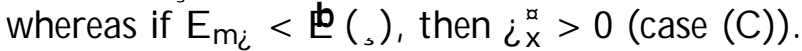

\section{Proposition 6.1}

Recall that in the two cases of endogenous and exogenous longevity the two median voters coincides, i.e., $E_{m_{i}}=E_{m_{i}}^{x}$, and $E_{m},=E_{m}^{x}$. Therefore, by Proposition 4.5 and 5.3, we immediately obtain case $B$, and cases $A$ and $C$, with the equality signs holding, i.e.e, in

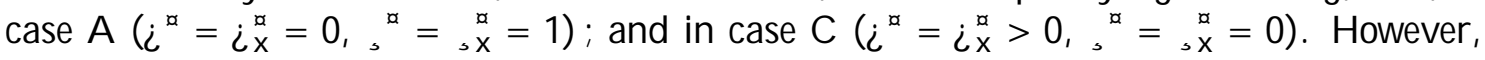
in the discussion of Proposition 4.5, we acknowledged that interior equilibria may arise in cases $A$ and $C$. Were these equilibria to exist, they would be on the downward sloping part of the reaction function $, E_{m},(i)$, in case $A$, and on the upward sloping part of $, E_{m},(i)$, in case $C$. T hus, in for these interior equilibria, we would have $\left(i^{x}>i_{x}^{\alpha}=0,,{ }^{x}<, x=1\right)$ in case $A$, and $\left(i^{\alpha}>i_{x}^{a}>0,{ }^{\infty}>, x_{x}^{\infty}=0\right)$ in case $C$.

Case (D) is more interesting. By Proposition 4.5 and 5.3, we know that if $E_{m}$, < $\mathrm{i}(1 \mathrm{i} \otimes), E_{m_{i}}<\mathrm{E}($,$) and E_{m_{i}}<-\left(E_{m}\right)$, then $\left(i^{\infty}>0 ;,{ }^{\infty}>0\right)$ and $\left(i_{x}^{\alpha}>0 ;, x=0\right)$. Notice that $i_{m_{i}}(,=0)=i_{x}^{\alpha}$. We will establish a sul cient condition for the two reaction functions, $E_{m},(i)$ and $i E_{m_{i}}($,$) to cross at a point \left(i^{\infty}>0 ;,{ }^{\infty}>0\right)$, which lies above the horizontal line $i=i_{x}^{a}=i_{m_{i}}(,=0)$. Let, e be the value of the reaction function of the median voter $E_{m}$, at $i_{x}^{\alpha}$ :

$$
e=, E_{m},\left(i_{x}^{\not a}\right)=\frac{1}{2} i \frac{1+E_{m,} i \quad \circledR}{2 E_{m},\left[4 i_{x}^{\not a}\left(1 ; \quad i_{x}^{\not a}\right)\right]}:
$$


Let ${ }_{2}^{b}$ be the positive value of, such that the reaction function of the median voter $E_{m_{i}}$ is equal to $i_{x}^{a}$ :

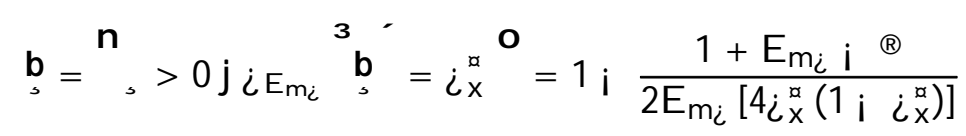

Notice that by Lemma $4.3, \Sigma_{\mathrm{m}_{i}}(\mathrm{l})$ is increasing ...rst and then decreasing, whereas, by Lemma 4.4, $, E_{m},(i)$ is increasing for,$>0$. Then, a su $\not$ cient condition for $i^{\infty}>i_{x}^{\infty}$ is that the reaction function, $E_{m},(i)$ crosses the horizontal line $i=i_{x}^{\alpha}$ to the left of the reaction function $i E_{m_{i}}($,$) , that is b, e$, , which, after simple algebra, can be stated as $E_{m},<\tilde{A}\left(E_{m_{i}}\right)=\frac{\left(1_{i 3} \otimes\right) E_{m_{i}}}{1_{i} \otimes_{i} E_{m_{i}} 1_{i} \frac{\left(1+E_{m_{i}}\right)^{2}}{\Theta^{2}(1+N)^{2}}}$. 


\section{R eferences}

[1] A nand, S. and M. Ravallion (1993) "Human Development in Poor Countries: On the Role of Private Incomes and Public Services", J ournal of Economic Perspectives 7 (1).

[2] Auerbach, Gokhale, and Kotlikox (1992)

[3] Boldrin, M. and Rustichini, A. (2000) "Equilibria with Social Security", Review of Dynamics E conomics.

[4] Boskin, M.J., L.J . Kotlikox, D.J . Puxert and J.B. Shoven (1987), "Social Security: A Financial A ppraisal across and within Generations", National Tax J ournal, 40.

[5] Conde-Ruiz, J .I. and V. Galasso (1999) "Positive A rithmetic of the Welfare State", CEPR Discussion Paper n. 2202.

[6] Conde-Ruiz, J .I. and V. Galasso (2000) "Early Retirement", CEPR Discussion Paper n. 2589.

[7] Cooley T.F., and J. Soares (1998) "A Positive Theory of Social Security Based on Reputation", J ournal of Political Economy, 107(1).

[8] Currie, Gruber and Fisher (1995).

[9] Cutler, D. and J. Gruber (1996) "Does public insurance crowd out private insurance?", Quaterly J ournal of Economics.

[10] Cutler, D. and J . Gruber (1997) "T he exect of M edicaid on Public Insurance, Private Insurance, and Redistribution", Health Economics, 86 (2).

[11] Cutler, D. and E. M eara (1997) "T he M edical Costs of The Young and Old: A Forty Year Perspective", NBER working paper n. 6114.

[12] Cutler, D. and E. Meara (1999) "The Concentration of Medical Spending: An Update", NBER working paper n: 7279.

[13] Cutler, D. and E. Richardson (1997)

[14] Cutler, D. and E. Richardson (1998) "The Value of Health: 1970-1990", American Economic Review, 88 (2).

[15] Deaton, A. (1999) "Inequalities in income and inequalities in health", NBER working paper n. 7141.

[16] Deaton, A. and C. Paxton (1998) "A ging and Inequality in Income and Health", American E conomic Review, 88 (2).

[17] Deaton, A. and C. Paxton (1999) "Mortality, education, income, and inequality among american cohorts", NBER working paper n. 7140.

[18] Epple, D. and R. Romano (1996) "Public Provision of Private Goods", J ournal of Political Economy, 104. 
[19] Galasso, V. (1999) "The U.S. Social Security System: What Does Political Sustainability Imply?", Review of Economic Dynamics, 2.

[20] Galasso, V. (2000) "The US Social Security: A Financial Appraisal for the Median Voter", CEPR Discussion Paper n. 2456

[21] Grossman, M. (1972) "On the Concept of Health Capital and the Demand for Health", J ournal of Political E conomy, 70 (2).

[22] Hammond P. (1975) "Charity: Altruism or Cooperative E goism" in "Altruism, M orality and Economic Theory" (E.S. Phelps, Ed.), Russell Sage Foundation, New York.

[23] Lee, McClennan and Skinner (1999) "The distributional exects of M edicare", NBER working paper n. 6910.

[24] Mulligan, C.B., and X. Sala-i-M artin (1999), "Gerontocracy, Retirement and Social Security", NBER working paper n. 7117.

[25] Philipson, T. and G. Becker (1998) "Old-A ge Longevity and Mortality-Contingent Claims", J ournal of Political E conomy, 106 (3).

[26] Shepsle, K. (1979) "Institutional Arrangements and Equilibrium In Multidimensional Voting Models", American J ournal of Political Science, 23 (1).

[27] Smith, J . (1999) "Healthy Bodies and Thick Wallets: The Dual Relation Between Health and Economic Status", J ournal of Economic Perspectives, 2.

[28] Tabellini, G. (1990), "A Positive Theory of Social Security", NBER Working Paper, $n^{0} 3272$.

[29] van Doorslaer et al. (1999) "The Redistributive Exect of Health Care Finance in twelve OECD Countries," J ournal of Health E conomics, 18 pp 291-313.

[30] Wilkinson (1996) 
Figure 1: US Social Security and Health Care

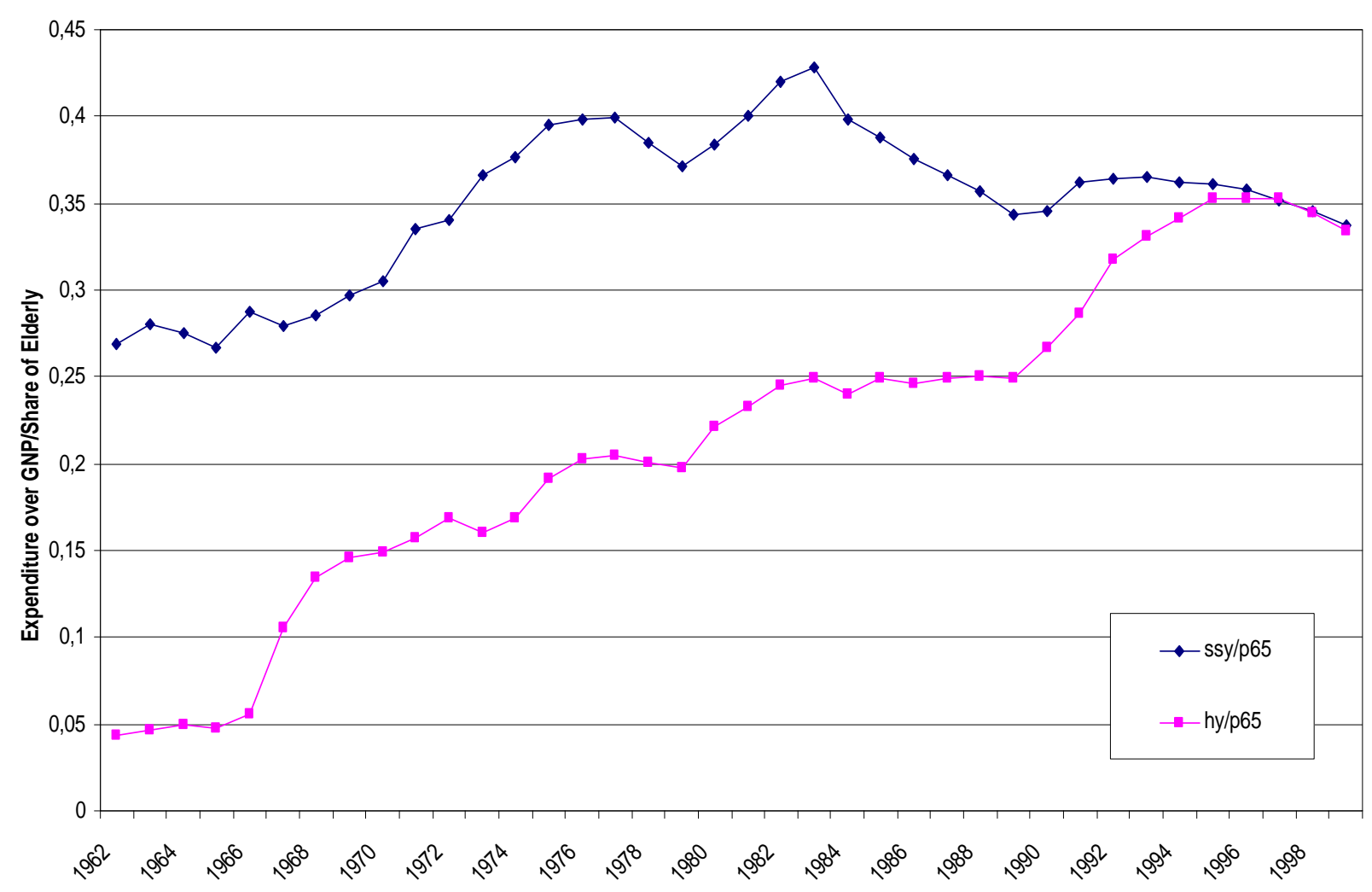

Figure 2: Longevity Function $\delta\left(e, H_{t}\right)$

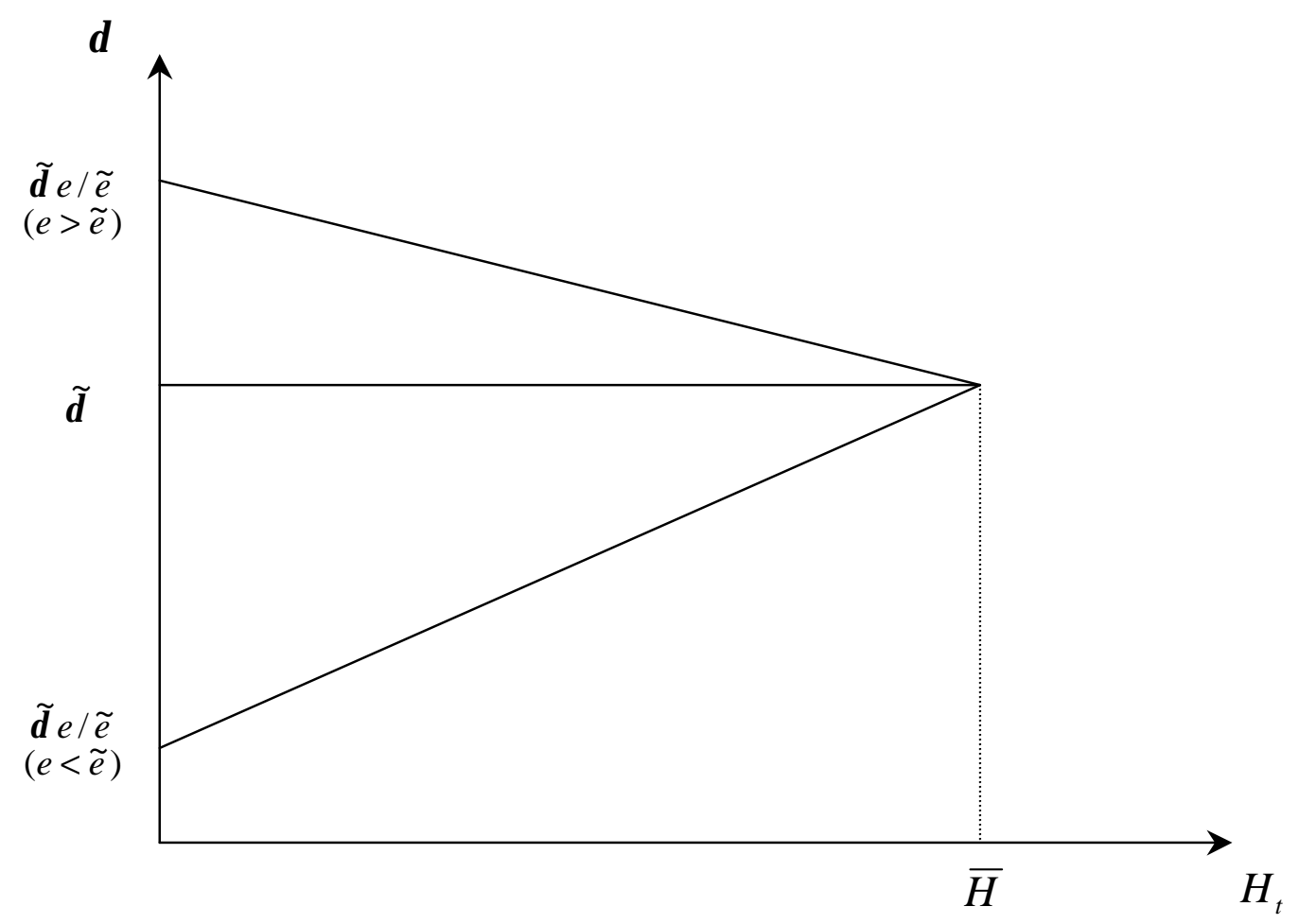


Figure 3: Voting over $\tau$

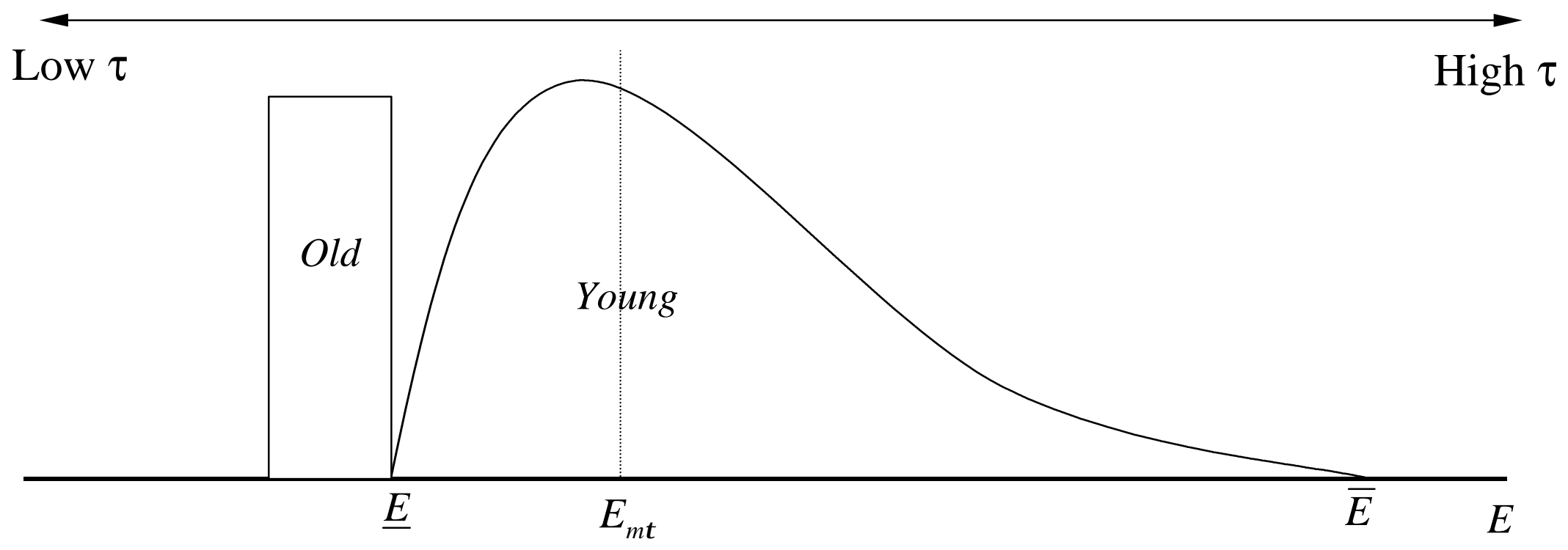

Figure 4: Voting over $\lambda$

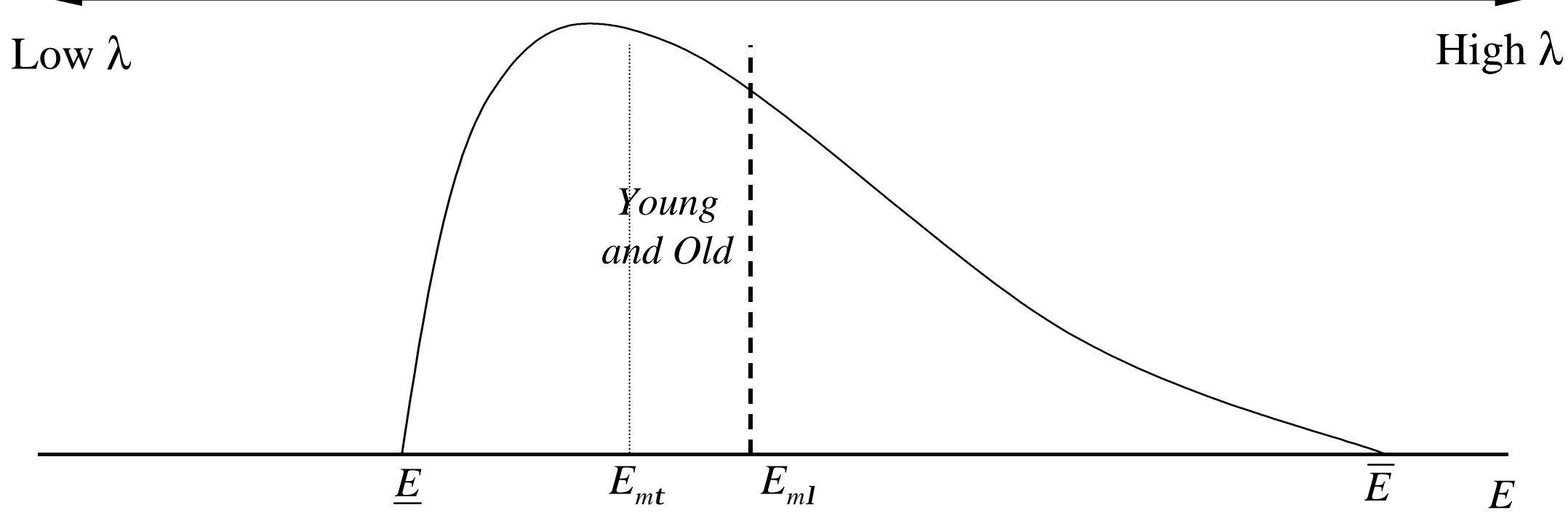


Figure 5: Case $(A)$

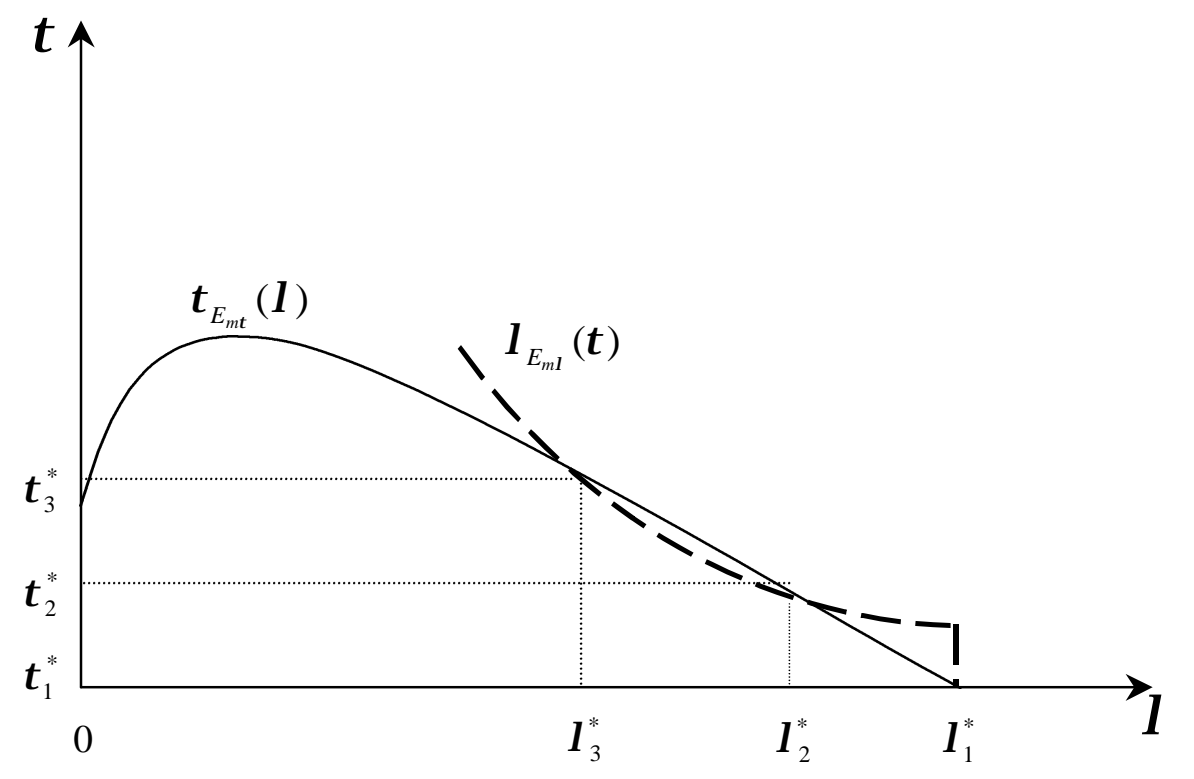

Figure 6: Case (D)

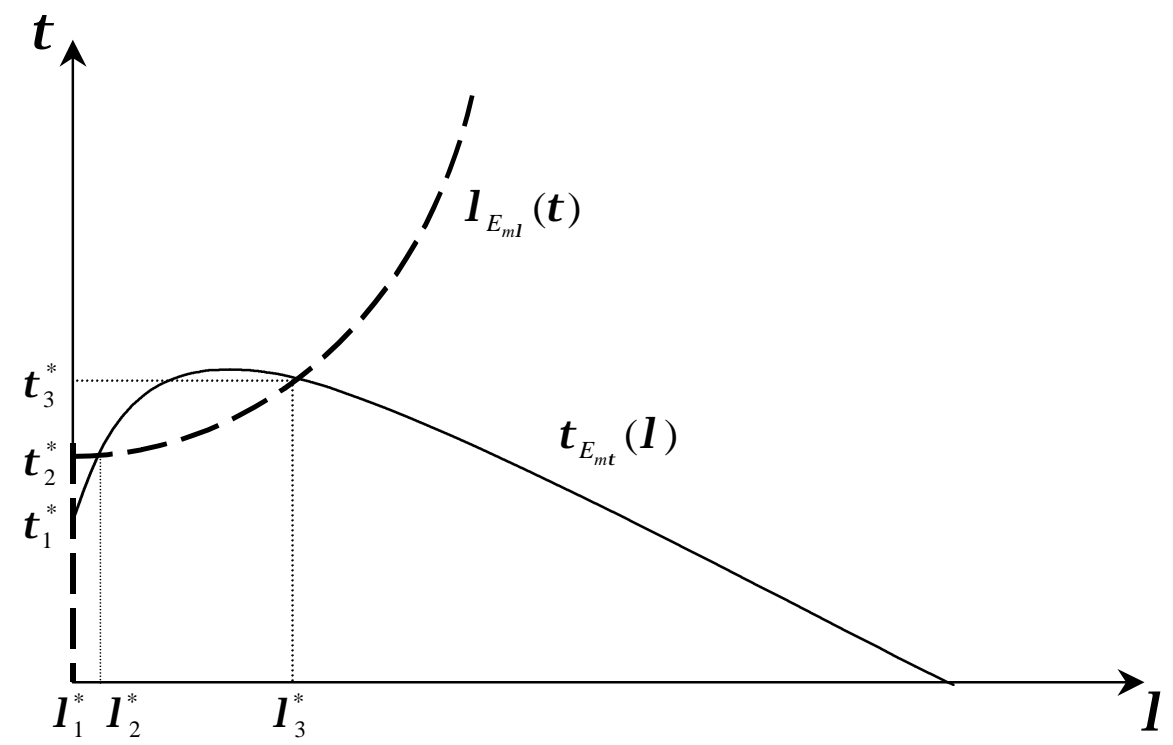


Figure 7

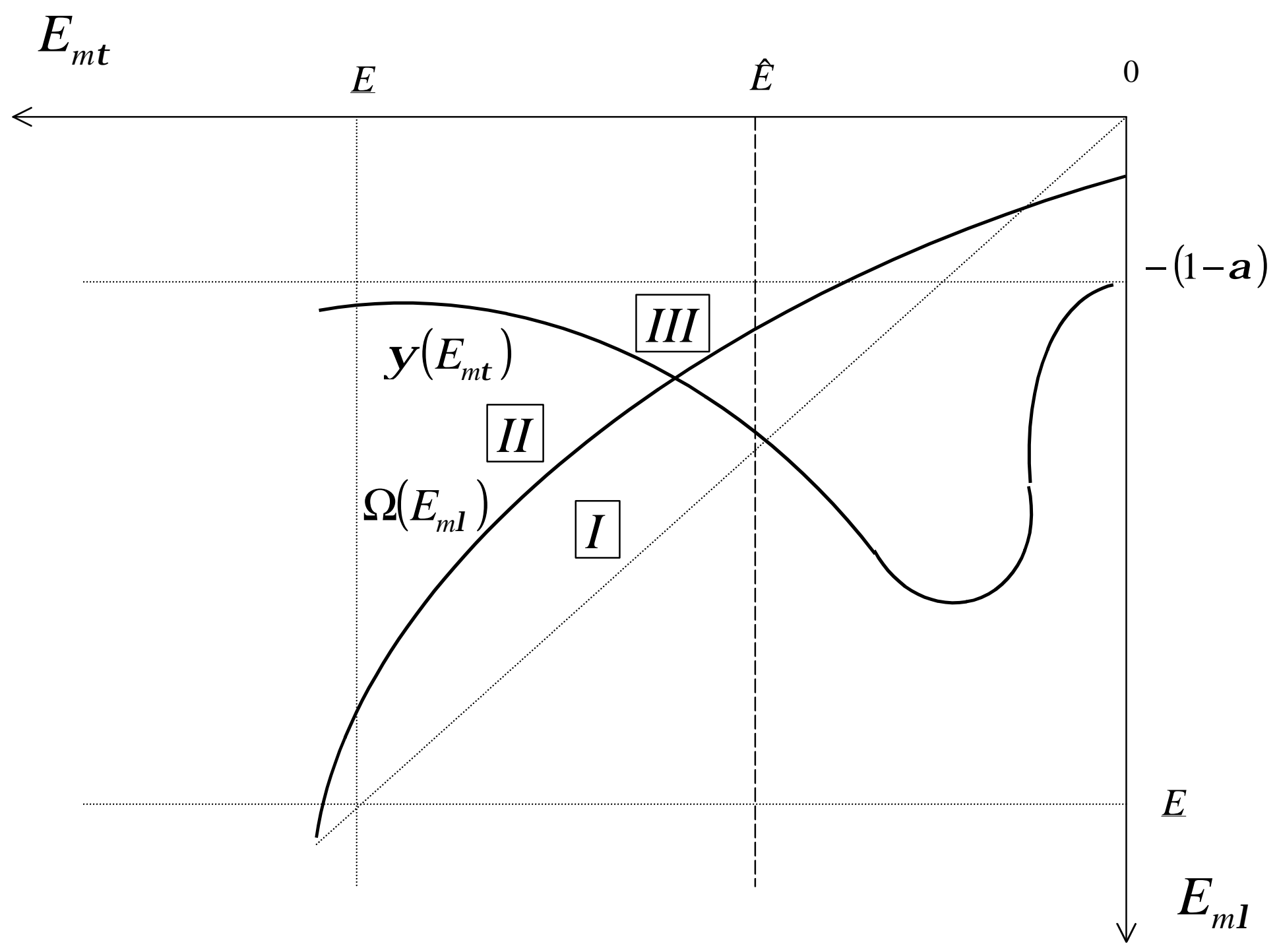

